\title{
Environmental animal models for sensorimotor gating deficiencies in schizophrenia: a review
}

\section{Journal Article}

\section{Author(s):}

Weiss, Isabelle C.; Feldon, Joram

Publication date:

2001

Permanent link:

https://doi.org/10.3929/ethz-b-000422996

Rights / license:

In Copyright - Non-Commercial Use Permitted

Originally published in:

Psychopharmacology 156(2-3), https://doi.org/10.1007/s002130100800 
Isabelle C. Weiss · Joram Feldon

\section{Environmental animal models for sensorimotor gating deficiencies in schizophrenia: a review}

Received: 10 January 2001 / Accepted: 4 April 2001 / Published online: 26 June 2001

(C) Springer-Verlag 2001

\begin{abstract}
Rationale: In schizophrenia research, the study of animal models has received considerable attention in the past 20 years. The value of animal models in preclinical research is widely recognised, largely because they can provide precious knowledge regarding the neurobiology of schizophrenia and can also be used for developing antipsychotic drugs. Prepulse inhibition (PPI; reduction in startle reflex induced by a prestimulus) is impaired in schizophrenic patients, a finding that has been associated with a loss of sensorimotor gating abilities. In rats, the schizophrenic-like PPI deficit can be induced by pharmacological or surgical manipulations targeting mainly the cortico-meso-limbic circuitry. Objectives: The literature was critically reviewed in an effort to determine the robustness and the relevance for schizophrenia of another category of animal models, based purely on manipulations of the social environment, that encompasses the neurodevelopmental hypothesis of schizophrenia. Specifically, we focused our attention on the long-term effects of such environmental models on sensorimotor gating processes as assessed in the PPI paradigm, with an attempt to evaluate their face, predictive and construct validity. Results: Our review of the literature leads to the conclusion that social deprivation performed directly after weaning ( 21 days of age) is more likely to be a relevant model for PPI impairments in schizophrenia than pre-weaning manipulations. Conclusions: Although the robustness of such environmental models requires further study, these animal models offer the advantage of avoiding invasive manipulations, which allows for a variety of anatomical, electrophysiological, neuroendocrine or neurochemical investigations in the
\end{abstract}

I.C. Weiss · J. Feldon ( $)$

Behavioral Neurobiology Laboratory, ETH, Zurich, Switzerland e-mail: feldon@toxi.biol.ethz.ch

Tel.: +41-1-6557448, Fax: +41-1-6557203

J. Feldon

Behavioral Neurobiology Laboratory,

Swiss Federal Institute of Technology, Postfach,

Schorenstrasse 16, 8603 Schwerzenbach, Switzerland absence of confounding pharmacological or surgical effects.

Keywords Schizophrenia $\cdot$ Prepulse inhibition - Animal models $\cdot$ Rat $\cdot$ Early handling $\cdot$ Maternal separation · Social isolation

\section{Introduction}

Schizophrenia is a neuropsychiatric disorder affecting approximately $1 \%$ of the population world-wide. It is characterised by positive (thought disorder, hallucinations, delusions) and negative (social withdrawal, anhedonia, flattening of affect) symptoms, the emergence of which considerably impairs the cognitive, intellectual and psychomotor abilities of those afflicted and handicaps their everyday life. Schizophrenia is a complex, multifactorial disease probably involving genetic, environmental and neurodevelopmental factors. Despite the fact that some chromosomal loci have been found to be related to the disease, no gene has been identified yet (Weinberger 1997; Tsuang 1998; Pulver 2000). In parallel, several hypotheses have emerged around the implication of environmental risk factors in the development of the disease. There is general agreement that the environment during pregnancy (e.g. intrauterine environmental stresses such as influenza exposure; Mednick et al. 1988; O'Callaghan et al. 1991; Takei et al. 1996), at birth (e.g. obstetrical complications; Owen et al. 1988) and/or during childhood is critical. The neurodevelopmental hypothesis of schizophrenia is based on the notion that these early-life environmental factors can have significant consequences for processes of brain maturation. Thus, several neuroanatomical abnormalities have been associated with schizophrenia, including ventricular enlargement, reduction in cortical volumes, particularly in the prefrontal cortex, and cytoarchitectural alterations of the limbic system, for example in the layers of the entorhinal cortex (Shelton and Weinberger 1986; Arnold et al. 1991). Interestingly, the prefrontal cortex, a cortical 
brain area widely implicated in the disease, reaches its functional maturity only in early adulthood, explaining perhaps why these early neurological injuries remain quiescent during childhood, "expressing" themselves only later, in adolescence, a time when schizophrenic symptoms often become apparent. Along these lines, Weinberger postulated that "if a lesion affects a brain structure or region that has yet to mature functionally, the effects of the lesion may remain silent until that structure or system matures" (Weinberger 1987). Furthermore, the observed reduction in cortical volume has been associated with neuronal loss but not with gliosis, suggesting that the pathology could be more related to an abnormal brain development than to atrophy. Finally, schizophrenia is not a neurodegenerative disease, because the anatomical abnormalities such as ventricular enlargement do not evolve with the illness.

As a part of the wide spectrum of symptoms exhibited by schizophrenic patients, their inability to ignore or "gate out" irrelevant external stimuli was described for the first time by Bleuler (1911). This loss of sensory gating abilities can be assessed using the prepulse inhibition (PPI) paradigm (described in detail in the following section). Briefly, PPI refers to the decreased startle to an intense stimulus when this stimulus is immediately preceded by a weaker pre-stimulus. Impaired sensorimotor gating in schizophrenic patients, as reflected by altered PPI, has been reported to lead to thought disorder and cognitive dysfunction (Braff et al. 1978, 1999; Grillon et al. 1992; Parwani et al. 2000). Nevertheless, PPI alterations are not specific to schizophrenia, but have also been reported in obsessive-compulsive disorder (Swerdlow et al. 1993b), Huntington's disease (Swerdlow et al. 1995b) or Tourette's syndrome (Smith and Lees 1989; Castellanos et al. 1996). Because PPI has the advantage of being a cross-species phenomenon that requires very similar stimulus parameters for both humans and rodents, animal models of deficient PPI have been developed with the aim of understanding the underlying pathophysiological mechanisms involved in the development of psychiatric diseases and being able to predict the antipsychotic potential of new compounds. This review will focus on animal models of human PPI deficiencies using environmental manipulations conducted in the early life of rats. Before defining these different environmental models and discussing their relevance to schizophrenia, we will first describe the PPI paradigm and its use in clinical research to investigate sensorimotor gating dysfunction in schizophrenic patients.

\section{Definition of startle reflex and prepulse inhibition}

The startle reflex

The startle reflex is a natural defensive response that involves a rapid contraction of facial and skeletal muscles and occurs in response to an unexpected, intense stimulus. The startle reflex is an uncontrolled, spontaneous re- sponse that can be elicited by stimuli originating from diverse sensory modalities (acoustic, tactile or visual). It can be observed in numerous mammalian species, including humans and rodents. In humans, the eyeblink reflex component of the startle response, i.e. the contraction of the orbicularis oculi facial muscle, is measured using an electromyography technique. In rats, the contraction of the whole-body muscles determines the amplitude of the startle reflex.

In mammalian species, a brain network composed of structures located in the lower brainstem and related to the motor nerves of the spinal cord mediates the startle reflex. Because the latency of the startle response is very short (between 5 and $10 \mathrm{~ms}$ ), this neural circuitry is thought to involve very few synapses. As described by Koch and Schnitzler (1997), the primary startle pathway includes several nuclei of the pontine reticular formation and their connections with motoneurons of the spinal cord governing the muscle contraction (Leitner et al. 1980; Davis et al. 1982; Koch and Schnitzler 1997). Several factors, like strain (Varty and Geyer 1998; Weiss et al. 2000), gender (Blaszczyk and Tajchert 1996; Weiss et al. 2001), light cycle (Frankland and Ralph 1995) or internal states such as fear or anxiety (Davis 1986) are known to influence the amplitude of the startle reflex in the rat. In addition, the startle reflex can show several forms of plasticity, including habituation or fear potentiation (Brown et al. 1951; Davis 1989; Davis et al. 1993), for which "higher" brain structures are required. Furthermore, the fact that the startle amplitude can be increased in states of fear (fear potentiation) or decreased in a pleasant context (pleasure attenuation; Lang et al. 1990; Koch et al. 2000), in both humans and rats, suggests that the startle amplitude can be used to evaluate emotional states (Marsh et al. 1973; Koch and Schnitzler 1997).

\section{Prepulse inhibition}

Prepulse inhibition (PPI) is a form of plasticity of the startle reflex. PPI is the normal reduction of the startle reflex to an intense acoustic stimulus (pulse) when this stimulus is immediately $(30-500 \mathrm{~ms})$ preceded by a weaker stimulus (prepulse) (Graham 1975; Braff et al. 1978; Hoffman and Ison 1980). PPI is usually expressed as a percentage of inhibition of the startle amplitude on prepulse+pulse trials as compared with the amplitude during pulse alone trials. The more salient the prepulse (higher intensity above background), the higher the percentage of inhibition of the startle reflex. In a later section, we will present unpublished data obtained using concomitantly an analysis in percentage PPI and an alternative method based on the effect size. An "effect size" analysis evaluates the extent to which a PPI modulation is produced by a treatment (i.e. an environmental manipulation), on the basis of which different studies can be directly compared.

Whereas the startle response is controlled by brain structures at the level of the brain stem, the mechanism 
of its inhibition by the prepulse requires forebrain structures (nucleus accumbens, hippocampus, amygdala or prefrontal cortex; Swerdlow et al. 1992a; Wan and Swerdlow 1997; Bakshi and Geyer 1998; Koch 1999; Pouzet et al. 1999; Zhang et al. 1999; Lacroix et al. 2000a). Therefore, PPI is a relevant model to investigate the neural control exerted by cortical and limbic structures on gating processes and the possible dysregulation of these processes in neuropsychiatric disorders. The brain seems to need a period of $30-500 \mathrm{~ms}$ to process correctly the information given by a first stimulus and therefore "gates out" or filters any new sensory event that might occur within this interval. This pre-attentive inhibitory process protects the brain against an overflow of information. The capacity of the prepulse to inhibit the startle reflex is thus an operational measure of the amount of sensorimotor gating. PPI is a reflexive phenomenon rather than a form of conditioning, because it can appear at the first presentation of the prepulse-pulse combination. Furthermore, PPI does not show habituation or extinction over repeated trials. As already mentioned above, because PPI deficits have been described in several psychiatric disorders, as well as in rats after activation of the dopaminergic mesolimbic system (for review, see Swerdlow et al. 1992a), the PPI paradigm used in rodents has been proposed as an animal model of the attentional impairments seen in these diseases, with face, predictive and construct validity (Geyer and Braff 1987; Swerdlow et al. 1992a; Swerdlow and Geyer 1998). Interestingly enough, because PPI can be studied in humans and rats using almost identical procedures and stimuli, it raises the possibility that the neurobiological mechanisms underlying the PPI response could be very similar across species.

\section{Sensorimotor gating deficiencies in schizophrenic patients}

There is general agreement that schizophrenic patients have difficulties to gate extraneous sensory stimulation. This deficit in their ability to filter incoming external information can lead to stimulus flooding and impairment of cognitive functioning. This pre-attentive process can be investigated in humans using either the PPI (Braff et al. 1978, 1992, 1999; Grillon et al. 1992; Perry et al. 1999; Parwani et al. 2000) or the P50 conditioning-test paradigm (Adler et al. 1982; Freedman et al. 1983). In the P50 conditioning test, an event-related potential response recorded on the vertex, with a positive wave delayed by $50 \mathrm{~ms}$ from the stimulus onset, is inhibited by the prior presentation of an identical stimulus using a 500-ms inter-stimulus interval. These sensory gating mechanisms have been demonstrated to be deficient in schizophrenic patients (Braff et al. 1992; Grillon et al. 1992; Bolino et al. 1994). Since the very first clinical studies of Braff et al. in the 1970s, which assessed the PPI response of schizophrenic patients, a number of interesting studies have "characterised" this sensorimotor gating deficit (Braff et al. 1978). First, PPI impairments in schizophrenic patients are described for both tactile and acoustic-elicited startle reflexes (Braff et al. 1992) and are not associated with changes of the startle reflex amplitude per se (Braff et al. 1992; Grillon et al. 1992). The latter findings suggest that schizophrenic patients can respond adequately to sensory stimuli of different modalities and that the deficit is independent of the nature of the pulse. Second, it seems that schizophrenic patients do not have problems to detect weak prepulses, and PPI deficits are apparent using a broad range of prepulse intensities (Grillon et al. 1992; Parwani et al. 2000). Third, disruption of PPI is still apparent after clinical remission of the symptoms in stable medicated patients, and does not differ from the disruption seen in an acute phase of psychotic symptoms (Parwani et al. 2000). Taken together, these findings strongly suggest that PPI deficits are an enduring feature of schizophrenia and that they reflect an abnormal information processing.

As already mentioned above, the deficient gating functions in schizophrenics as reflected by altered PPI are thought to be related to cognitive disabilities. In a recent study, Perry et al. (1999) reported that PPI impairments correlated with "perceptual inaccuracy and disordered cognitive reasoning" in schizophrenic patients. Together with a previous study from the same authors (Perry and Braff 1994), the latter finding supports the contention that deficient sensorimotor gating in schizophrenics may result in thought disorder and distractibility. Although the latter reports might suggest that PPI impairments are more related to the positive symptomatology of schizophrenia, some studies have also reported relationships between PPI dysfunction and negative symptomatology (Braff et al. 1999). In contrast, Parwani et al. (2000) found no correlation between gating deficits and clinical symptomatology. It remains therefore unclear whether PPI deficits can be "categorised" in clinical scoring, although it does seem reasonable to consider this disruption as a substantial neurobiological marker of the disorder.

\section{Modelling sensorimotor gating deficits in the rat}

In animals, the schizophrenic-like PPI deficit has to be induced such that it resembles the human dysfunction (face validity). The induction of PPI deficits by means of pharmacological or surgical manipulations has been studied over the past twenty years and these approaches are now widely employed to affect PPI. Nevertheless, these models have certain intrinsic limitations that can be avoided by the use of environmental models. Although it is not within the scope of this review to discuss the different pharmacological and lesion models for PPI disruption (for review, see Swerdlow et al. 2000a), we will present here some examples.

Dopaminergic dysfunction in the mesolimbic system has been repeatedly implicated in schizophrenia (Snyder 1976; Seeman et al. 1984; Bachus and Kleinman 1996; 
Knable and Weinberger 1997). In line with this dopaminergic hypothesis, PPI deficits can be obtained by acute pharmacological manipulation of the mesolimbic system (Swerdlow et al. 1992b). For example, systemic administration of apomorphine (a direct dopamine agonist; Rigdon 1990; Swerdlow et al. 1994; Varty and Higgins 1995; Depoortere et al. 1997a; Mansbach et al. 1998) or amphetamine (an indirect dopamine agonist; Mansbach et al. 1988; Swerdlow et al. 1990) disrupts PPI dosedependently in the rat. These observations are consistent with the finding that PPI can be attenuated in non-psychiatric controls by systemic injections of amphetamine (Hutchison and Swift 1999). Furthermore, the apomorphine-induced PPI disruption can be reversed by antipsychotic drugs such as clozapine (Swerdlow and Geyer 1993), haloperidol, or raclopride (Varty and Higgins 1995), an observation that supports the predictive validity of disrupted PPI as an animal model of schizophrenia (Kumari et al. 1999). Although the pharmacological disruption of PPI with dopaminergic agents seems to be robust and stable, it also presents some limitations. First, the pharmacological induction of PPI deficits is sometimes hardly reversed by atypical antipsychotics known to be effective in schizophrenia. For example, in some studies, clozapine failed to reverse the apomorphineinduced disruption of PPI (Rigdon and Viik 1991; Varty and Higgins 1995). Second, Davis et al. (1990) have demonstrated that apomorphine-induced PPI deficits were only observed when the difference between the background noise and the stimulus was below $10 \mathrm{~dB}$, raising the possibility of an interaction of the drug with the detection of the prepulse stimulus. Third, in the context of basic research, this pharmacological induction of PPI deficits biases the investigations towards a specific neurotransmitter system. Finally, in the context of drug screening, this pharmacological model automatically implicates drug-drug interactions and tends to select pharmacological homologues: for example a dopaminergic antagonist with potential antipsychotic properties will reverse the PPI deficit induced by a dopamine agonist.

Lesions and intracerebral infusions have also been employed to disrupt PPI in adult animals by targeting a specific brain area. For example, lesion of the ventral striatum or the medial prefrontal cortex has been reported to reduce PPI (Koch and Bubser 1994; Kodsi and Swerdlow 1994; Yee 2000), although not consistently (Swerdlow et al. 1995a; Lacroix et al. 1998). Temporary NMDA-induced overactivity of the ventral hippocampus, but not dorsal hippocampus (W. Zhang, T. Bast and J. Feldon, unpublished observations), is reported to severely impair PPI (Klarner et al. 1998; Koch et al. 1999; Zhang et al. 1999). These intracerebral NMDA infusions mimic the hippocampal overactivity apparent in certain schizophrenic patients (Friston et al. 1992; Heckers et al. 1998). However, the predictive validity of this model still needs to be demonstrated, because pre-treatment with systemic haloperidol does not reverse the deficit and there is controversy in the literature concerning the ability of clozapine to reverse this disruption (Zhang et al. 1999; Bast et al. 2001). In line with this glutamatergic hypothesis, systemic administration of non-competitive NMDA antagonists, such as phencyclidine (PCP), dizocilpine (MK-801) or ketamine is also used to disrupt PPI in rats (Mansbach and Geyer 1989; Keith et al. 1991; Hoffman et al. 1993; Swerdlow et al. 1998; Feifel and Priebe 1999; Bast et al. 2000; for review, see Swerdlow and Geyer 1998). Furthermore, this model is consistent with the research in humans, since PPI is also impaired in human volunteers following treatment with NMDA antagonists (Vollenweider et al. 2000).

One lesion model that is line with the neurodevelopmental hypothesis of schizophrenia has been developed by Lipska et al. (1993), and consists of lesioning the ventral hippocampus of 7-day-old pups. These neonatally lesioned rats demonstrated behavioral and neurochemical alterations, including deficient PPI at postnatal day 56 (post-puberty) but not at postnatal day 35 (pre-puberty) (Lipska et al. 1995), which is suggestive of late induction of increased dopamine function in the mesolimbic system (construct validity). Interestingly enough, this model presents face validity by mimicking some of the characteristics of schizophrenia, such as post-pubertal onset of behavioural abnormalities, congenital hippocampal area damage, or dysfunction of the limbic dopaminergic system. However, the predictive validity of the model still needs to be confirmed, as no data are available yet regarding the effects of typical or atypical neuroleptics on this lesion-induced PPI deficit. Furthermore, since an early brain lesion is involved, it is very difficult to judge to what extent the lesion will interfere with normal brain development and have deleterious effects on other connected brain regions. Moreover, the research will be automatically dominated by the a priori implication of a specific brain area in the behavioural outcome in adulthood.

A promising alternative to these models can be seen in the study of non-invasive animal models for deficient PPI, an approach that has received considerable attention over the past 10 years. These models, based on manipulations of the social environment of animals during specific developmental periods, emerged from the observation that developing rodents demonstrate a high sensitivity to early life manipulations of their social environment. In contrast to the acute effect produced by a systemic drug injection or infusion, the environmentally induced disruption of PPI allows the investigation of the effects of the manipulation over a long period of time. In addition, such models can be relevant in the context of the neurodevelopmental hypothesis of schizophrenia. Interestingly, environmental animal models offer the advantage of avoiding invasive manipulations and thus are suitable for a variety of investigations at the anatomical, electrophysiological or neurochemical levels in the absence of confounding pharmacological or surgical effects. Therefore, the study of such models can also yield information that may further enhance the understanding of the pathophysiological mechanisms involved in the development of psychiatric diseases such as schizophre- 
nia. Finally, if an environmental model shows face, predictive and construct validity for schizophrenia, it can represent a novel and very interesting approach for the detection of potential antipsychotic drugs with the PPI paradigm. In the following sections, we will present these different environmental models in rats in association with their possible long-term effects on sensorimotor gating abilities, and their validity for schizophrenia.

\section{Environmental animal models of deficient sensorimotor gating}

Derived from the hypothesis that brain maturation processes are more susceptible to permanent modification when intervention occurs at an early age, several noninvasive animal models use manipulations of the earlylife social environment, mainly by isolating the animals from the social group for a certain period of time. As such, social deprivations can be conducted during specific phases of development, either during the pre-weaning period, or from weaning to adulthood or only during adulthood. Early handling, maternal separation and social isolation are the three different environmental manipulations whose effects on PPI have been studied.

\section{Early handling}

Early handling $(\mathrm{EH})$ is the most commonly studied preweaning manipulation of the social environment and one that gives rise to relatively consistent and well-defined behavioural and neuroendocrine effects in adult animals. $\mathrm{EH}$ consists of daily separations of pups from their mother for 3 to $15 \mathrm{~min}$, which does not exceed the normal period of separation that occurs when the mother leaves the nest. Therefore, EH has not been described as representing a social deprivation for the animals and is indeed considered to stimulate maternal care (Liu et al. 1997). EH has been reported to facilitate the maturation of brain limbic structures (Levine 1994; Meaney et al. 1994), thereby having a somehow "protective" effect in the long term, for example by delaying age-related neural and cognitive deficits (Meaney et al. 1988, 1991; Pham et al. 1997). The behavioural and endocrine consequences of EH are typically reported using a control group of non-handled $(\mathrm{NH})$ rats, reared either totally undisturbed during the pre-weaning period (no cage cleaning) or under normal husbandry conditions (regular cage cleaning). When exposed to stress, compared to totally undisturbed $\mathrm{NH}$ rats, handled rats demonstrate in adulthood decreased emotional responses, reduced hypothalamic-pituitary-adrenal (HPA) axis responsiveness, as revealed by a reduction of corticosterone release, and a rapid post-stress endocrine recovery (Levine 1967; Meaney et al. 1989, 1996). Nevertheless, when EH animals are compared with normal-husbandry controls, the endocrine differences are much weaker (Campbell and Spear 1999). Furthermore, EH has been reported to in- fluence many aspects of behaviour. Compared to $\mathrm{NH}$, EH rats are more active and show more exploration when confronted with novelty, they demonstrate reduced anxiety in the elevated plus maze (Vallee et al. 1997), and their locomotor response to $d$-amphetamine is also increased (Weinberg et al. 1978; Feldon and Weiner 1988). In contrast, relative to normal-husbandry controls, EH does not affect spontaneous or $d$-amphetamine induced locomotor hyperactivity in a circular corridor (Campbell and Spear 1999). EH rats have been reported to exhibit better performance in learning tasks (Weiner et al. 1985, 1987), reduced food-related neophobia and better discrimination, which could be attributed to their lower emotional reactivity (Weinberg et al. 1978). Finally, latent inhibition (i.e. retarded conditioning to a stimulus that has previously been repeatedly presented without meaningful consequences) is not affected by $\mathrm{EH}$, but is disrupted in NH male rats (Weiner et al. 1985; Feldon et al. 1990), the disruption being reversed by haloperidol (Feldon and Weiner 1988).

\section{Maternal separation}

It was in the 1960s that Harlow and Harlow conducted the first studies on the effects of early social deprivation in monkeys (Harlow and Harlow 1962). When reared from birth in artificial conditions devoid of any social contact with their mother or peers, infant monkeys exhibited severe behavioural abnormalities, including stereotypic behaviour, lack of grooming, or social withdrawal when confronted with a group of congeners; the latter behaviours were seen as signs of depression. In the newborn laboratory rat, the social environment is defined by interactions with the mother and littermates. The mother constitutes thus the unique link between the pups and the external world. Variations in maternal care can destabilise the mother-infants interaction, thereby producing profound alterations in the maturation of the pups. In the rat, pre-weaning maternal separation (MS) consists of separating pups from their mothers for a longer period of time (1-24 h) than in EH. In addition to the duration of the mother-pups separations, there is evidence that the frequency of these separations and the time point at which they are conducted during the preweaning period differentially modify the subsequent behavioural responses (for review, see Lehmann and Feldon 2000). These experimental variables vary largely across laboratories and may explain some of the discrepancies apparent in the outcomes. Furthermore, other experimental factors, such as the degree of social deprivation can differ. Indeed, when the pups are separated from their mother, they can be further separated from their littermates (Zimmerberg and Shartrand 1992; McIntosh et al. 1999; Pryce et al. 2001) or kept together (Lehmann et al. 2000a, 2000b). In the first case, the social deprivation is complete, whereas in the second case littermates are less disturbed (partial social deprivation). It is, in fact, a natural situation for a pup to stay alone with its 
littermates for a short period of time when the mother is engaged in feeding, drinking, or self-grooming behaviours. Although it is not clear what is more disturbing for the rats, i.e. the absence of the mother or the peers, the complete social deprivation is more likely to produce greater developmental alterations. In addition, the temperature at which the pups are kept during separation from the mother seems to be a critical factor in the development of the dopaminergic system in the brains of MS animals (Zimmerberg and Shartrand 1992). Finally, the control group chosen to evaluate the MS-induced effect differs between studies, being composed of totally non-disturbed animals, handled rats, or non-maternally separated (NMS) controls reared in normal husbandry conditions (for review, see Lehmann and Feldon 2000).

Maternal separation implies a severe loss of maternal care, including nutrition and warmth, and as such is considered to be a major social deprivation that alters significantly the development of the brain and the neuroendocrine system, which in turn leads to permanent behavioural and physiological modifications in the adult animals. Although these MS-induced alterations have been proposed to be opposite to those of EH (Anisman et al. 1998; Hall 1998), recent data from our laboratory have not always provided support for this statement. Maternally separated animals show altered open field spontaneous locomotor activity (Zimmerberg and Shartrand 1992; Lehmann et al. 1999a, 2000b), reduced sensitivity to $d$-amphetamine (Zimmerberg and Shartrand 1992; Matthews et al. 1996) but increased sensitivity to apomorphine (Ellenbroek and Cools 1995; Rots et al. 1996), altered hypothalamo-pituitary-adrenal axis (HPA) functioning and enhanced (Stanton et al. 1988; Meaney et al. 1996) or decreased (I. Weiss and C. Pryce, unpublished observation) corticosterone responsiveness to stressors. Finally, MS was shown to either disrupt latent inhibition (Ellenbroek and Cools 1995) or enhance it (Lehmann et al. 1998, 2000b; Weiss et al. 2001).

\section{Social isolation}

In rodents, social isolation (SI) can be performed from weaning ( 21 days of age) to adulthood, i.e. in the adolescent rat (isolation-rearing, IR), or when the rat is already adult (isolation-housing, IH). In both paradigms, normal social contacts and play are prevented by placing the animals in single cages, reducing considerably the amount of sensory stimulation. The consequences of such social deprivations are commonly evaluated in adulthood in comparison with control subjects reared in a social environment of two to four rats per cage. Moreover, in most studies the animals are kept in the same room. Thus, isolates can maintain visual, auditory and olfactory contacts with their counterparts, although to a lesser extent. However, since IR is conducted during the developmental period from weaning to adulthood, it deprives the animals of social contacts during a critical phase of their life span characterised by the development of social play (Einon and Morgan 1977). This environmental manipulation can thus potentially alter the maturation of cerebral structures, such as those involved in the cortico-striato-limbic circuitry. Atlhough the neurogenesis in the above-mentioned brain regions is completed at weaning, some neural connections between the structures of this cortico-striato-limbic circuitry may not be completely established. Indeed, isolation-reared adult rats exhibit profound and long-lasting alterations of their behavioural profile, including spontaneous hyperactivity in open field environments (Sahakian et al. 1975; Gentsch et al. 1988; Rebouças and Schmidek 1997; Weiss et al. 2000), although absent in isolates from the SpragueDawley strain (Geyer et al. 1993; Weiss et al. 2000), and altered responsiveness to psychostimulants (Phillips et al. 1994; Wongwitdecha and Marsden 1995). In addition, IR rats demonstrate neophobia (Morgan et al. 1975; Gentsch et al. 1982; Hall et al. 1997b), increased timidity (Einon and Morgan 1977), increased anxiety (Wright et al. 1991), and perseverative behaviours (Morgan and Einon 1975; Dalrymple-Alford and Benton 1984). Moreover, IR seems to affect cognitive learning in diverse tasks (Greenough et al. 1972; Gardner et al. 1975; Holson 1986; Weiss et al. 2001), although some conflicting results exist regarding the IR effect on spatial learning tasks (Wongwitdecha and Marsden 1996; G. Gregorian, I. Weiss and J. Feldon, unpublished observations). Finally, IR does not affect LI (Feldon et al. 1990; Wilkinson et al. 1994; Weiss et al. 2001). It has been proposed that IR constitutes a chronic stressor (Hatch et al. 1965; Holson et al. 1991), thereby producing long-term endocrine alterations. Nevertheless, the findings have not been consistent in this regard; IR rats are reported to have increased (Hatch et al. 1965; Gamallo et al. 1986; I. Weiss and C. Pryce, unpublished observations), decreased (Sanchez et al. 1995) or similar (Morinan and Leonard 1980; Gentsch et al. 1981; Holson et al. 1988, 1991) basal levels of corticosterone relative to grouped controls. Finally, neurochemical alterations have been described after IR, indicating a reduced dopamine turnover in the medial prefrontal cortex and serotoninergic alterations in the nucleus accumbens and amygdala (Jones et al. 1991; Fulford and Marsden 1998; Heidbreder et al. 2000).

In contrast, IH is conducted in adult animals and generally for a shorter period of time (several weeks). The behavioural, endocrine or neurochemical consequences of IH have been less studied, and seem generally to be less profound than those of IR. Rats isolated in adulthood demonstrate spontaneous hyperactivity in open fields, increased locomotor response to systemic amphetamine administration, and increased timidity towards novel environments (Ahmed et al. 1995). In addition, IH has been reported to impair water maze learning (Wade and Maier 1986). Similarly to IR, the effects of IH on endocrine systems are not consistent between the studies, with either increased (Lovely et al. 1972), decreased (Miachon et al. 1993) or similar basal corticosterone levels (Niesink and van Ree 1983; Giralt and Armario 1989) being reported. Although the neurochemical alter- 
ations apparent as a consequence of IH are not clearly defined in the literature, some ex-vivo studies have demonstrated reduced dopaminergic metabolism in the nucleus accumbens and generally reduced serotonin function (for review, see Hall 1998).

\section{Chronic effect of EH on acoustic startle and PPI}

Whereas the effects of the pre-weaning environmental manipulation of $\mathrm{EH}$ have been largely investigated in terms of behavioural and endocrine alterations (see above), to the best of our knowledge, no report exists in the literature on the consequences of $\mathrm{EH}$ on startle reflex and PPI. However, in recent studies conducted in our laboratory, EH rats were found to have normal sensorimotor gating abilities relative to non-handled or normalhusbandry controls (Pryce et al. 2001; J. Lehmann and J. Feldon, unpublished observations). In addition, the startle reflex amplitude was not affected by EH. Although further studies are required to confirm this finding, it suggests that EH may not be an appropriate model to investigate the neurobiological basis of deficient sensorimotor gating in schizophrenia.

\section{Chronic effect of MS on acoustic startle and PPI}

Several very recent studies were conducted to analyse the consequences of MS on startle reflex and PPI in adulthood. The majority of studies did not find any effect of MS $(1 \times 24 \mathrm{~h}$ MS or $21 \times 4 \mathrm{~h}$ MS) on startle reflex amplitude (Ellenbroek et al. 1998; Ellenbroek and Cools 2000; Finamore and Port 2000; Lehmann et al. 2000a; Weiss et al. 2001). In contrast, discrepancies are apparent concerning the effects of MS on PPI. PPI has been reported to be either impaired (Ellenbroek et al. 1998; Ellenbroek and Cools 2000) or not affected by MS (Feldon et al. 2000; Finamore and Port 2000; Lehmann et al. 2000a, 2000b; Weiss et al. 2001). Several methodological parameters may explain this inconsistency. First, the effect may depend on the strain of rats; no effect of MS on PPI was found in the Sprague-Dawley (Feldon et al. 2000; Finamore and Port 2000; Weiss et al. 2001), Lewis or Fisher 344 strains (Ellenbroek and Cools 2000). In addition, MS rats from the Wistar strain reared in the Netherlands demonstrated PPI deficits (Ellenbroek et al. 1998; Ellenbroek and Cools 2000), whereas MS rats from the Wistar strain reared in Switzerland showed similar PPI to that of NMS controls (Lehmann et al. 2000a, 2000b). The latter suggests that although the rats from these two laboratories originated from the Wistar strain, their phenotype may be different due to different animal suppliers (Swerdlow et al. 2000b). A second element that goes in line with genetics playing a major role in the behavioural effects of MS on PPI, is the control of the independence of the subjects. Indeed, it is important that the experimental groups be composed of unrelated subjects from different litters. For example, in the studies of both Ellenbroek et al. (1998) and Lehmann et al. (2000a), a single 24-h MS was conducted at postnatal day 9 in Wistar rats. Therefore, one of the most likely explanations for the discrepant findings could be that in the study of Ellenbroek et al. (1998), because all the subjects originated from a limited number of mothers ("litter effect" in terms of genetical background and maternal care), the likelihood of obtaining a statistically significant effect of MS on PPI was increased (see Lehmann et al. 2000a for more details). Another difference between the studies of Ellenbroek and ours is the temperature at which the pups were kept during the MS procedure, which, as we have already pointed out, can have major consequences for the development of the dopaminergic system. In the studies of Ellenbroek (Ellenbroek et al. 1998; Ellenbroek and Cools 2000), the pups were kept at room temperature, which can be assumed to be around $20-22^{\circ} \mathrm{C}$, whereas in our studies the pups were kept in incubators or on heating pads at a higher temperature (between $25^{\circ} \mathrm{C}$ and $33^{\circ} \mathrm{C}$ depending on the study; Feldon et al. 2000; Lehmann et al. 2000a, 2000b; Weiss et al. 2001). Third, despite the fact that the degree of social deprivation was different between studies (complete or partial social deprivation of the pups), this factor did not seem to influence the MS effect on PPI. Indeed, MS was found not to affect PPI irrespective of whether the pups were also separated from each other (Feldon et al. 2000; Finamore and Port 2000; Weiss et al. 2001) or kept together (Lehmann et al. 2000a, 2000b). Fourth, the fact that in our laboratory, MS was never found to alter PPI (irrespective of rat strain), whether it was performed as a single 24-h MS, as $4 \times 6-\mathrm{h}$ MS or as repetitive 4-h daily MS for the entire pre-weaning period, suggests that the effect of MS on PPI (or its lack) is independent of the developmental period at which the MS procedure takes place. Finally, the gender of the rats does not seem to influence the MS effect on PPI, since in all studies where MS was conducted in both males and females, no interaction between MS and gender was found (Ellenbroek et al. 1998; Finamore and Port 2000; Lehmann et al. 2000a, 2000b).

In conclusion, we are inclined to suggest that MS does not consistently affect PPI. Although the studies from Ellenbroek et al. (1998; Ellenbroek and Cools 2000) on Wistar rats are suggestive of face (MS induces PPI deficits), predictive (MS-induced PPI deficits were reversed by haloperidol and quetiapine; Ellenbroek et al. 1998) and construct validity (enhanced sensitivity of MS rats to the dopamine agonist apomorphine; Ellenbroek and Cools 2000), these findings all originate from one laboratory, using only one strain and MS procedure, and have not been confirmed by others, where different strains, unrelated subjects and a range of MS procedures were employed (Feldon et al. 2000; Finamore and Port 2000; Lehmann et al. 2000a, 2000b; Weiss et al. 2001). Further studies are thus required to validate the model, because an important step in this direction involves obtaining inter-laboratory reproducibility. 


\section{Chronic effect of SI on acoustic startle and PPI}

Although the potential of SI to disrupt sensorimotor gating in rats has been studied only relatively recently (Geyer et al. 1993), nowadays it is widely reported in the literature that rats isolated from weaning to adulthood (but not isolation-housed rats) demonstrate deficits in the PPI paradigm. Consequently the IR model has attracted considerable interest for the screening of novel antipsychotic drugs, but also towards understanding the underlying neurobiological dysfunctions in psychiatric disorders characterised by deficient PPI. That rats, isolated when they were immature, could show PPI impairment in adulthood, mimicking abnormal sensorimotor gating in schizophrenic patients, is suggestive of face validity. In addition, SI-induced PPI deficits have been reversed in rats by a range of antipsychotic drugs, including raclopride (Geyer et al. 1993; Varty and Higgins 1995), haloperidol, risperidone, clozapine (Varty and Higgins 1995), seroquel or olanzapine (Bakshi et al. 1998), suggesting that an IR-induced PPI deficit has predictive validity for schizophrenia. Indeed, in a recent study, Weike et al. (2000) report that, in schizophrenic patients, neuroleptic treatment can reduce PPI deficits. Finally, this model also has construct validity, as PPI dysfunctions have been associated with DA hyperactivity in the brains of IR rats (particularly in the nucleus accumbens; Jones et al. 1992), and of schizophrenic patients (Meltzer and Stahl 1976; Weinberger 1987; Bachus and Kleinman 1996; Egan and Weinberger 1997; Abi-Dargham et al. 2000). Furthermore, and as already mentioned above, this model offers the advantage of conforming to the neurodevelopmental theory of schizophrenia, since both in schizophrenics and in IR rats, an alteration of the normal development has permanent consequences for subsequent adult behaviour.

The effects of IR on startle reflex are not consistent between the studies; IR has been reported either to increase (Wilkinson et al. 1994; Varty and Higgins 1995; Weiss et al. 1999) or not to modify (Geyer et al. 1993; Domeney and Feldon 1998; Bakshi and Geyer 1999; Weiss et al. 2000) the startle reactivity of the animals. The startle reflex is a very plastic response which can be modulated by many factors (see below) and used to evaluate emotional states (Marsh et al. 1973; Koch and Schnitzler 1997). In this context, if we consider IR as a type of chronic stressor (Hatch et al. 1965; Holson et al. 1991), then the modulation of the startle amplitude by IR can represent an interesting tool in its own right to investigate the influence of fear/anxiety states on processes of information filtering.

Post-weaning social isolation offers thus a valuable non-pharmacological model to disrupt PPI and to further identify new antipsychotic drugs. Therefore, experimental and pharmacological validations have been and are still performed on this model to obtain a reliable and robust PPI disruption. Nevertheless, several studies performed in our laboratory pointed out the fragility of this SI-induced PPI disruption by demonstrating the sensitiv- ity of the model to experimental conditions and stimulus parameters. This could limit its potential as an animal model for drug screening. We propose to review in the following paragraphs some of the critical methodological parameters that are known to influence the SI-induced PPI deficit and that should be carefully considered prior to embarking on investigations with this animal model. In addition, because of the apparent fragility of the SIinduced PPI deficit, at least in our laboratory, we propose to analyse the PPI data using another method to evaluate the effect size of the IR treatment (see below). We will give an example in the present review, by presenting original data regarding two additional parameters which might affect the robustness of the model and have not yet been studied systematically (see below).

\section{Strain of rats}

The startle and PPI responses of untreated animals have been shown to vary considerably between different strains of rats. Therefore, several research groups have compared different rat strains in the PPI paradigm towards understanding the contribution of genetic background to PPI alterations apparent in schizophrenic patients. We will present here some examples that we think may be relevant for the induction of PPI deficits following IR. It has been recently reported by Kinney et al. (1999) and Swerdlow et al. (2000b) that the sensitivity of the PPI response to dopaminergic agonists can vary not only between rat strains but within the same strain, depending on the animals' supplier. For example, across laboratories, Wistar rats seem to show PPI deficits following administration of apomorphine $\left(\mathrm{D}_{1} / \mathrm{D}_{2}\right.$ dopamine agonist) more consistently than rats from the SpragueDawley strain (Rigdon 1990; but see Varty and Higgins 1994). On the other hand, despite their variable startle response (Weiss et al. 2000) and sensitivity to dopamine agonists, the different strains of rats frequently show similar levels of PPI; this holds true for Lewis, SpragueDawley and Fischer rats in the study of Varty and Geyer (1998), for Lister hooded, Sprague-Dawley and Wistar rats (Rigdon 1990; Weiss et al. 2000), but not for Wistar and Fawn hooded rats from the study of Hall et al. (1997a). However, two studies have shown significant differences of the Wistar strain in sensitivity to PPI. First, Varty et al. (1994) reported that Wistar rats are less sensitive in both the detection and processing of the prepulse stimulus than Sprague-Dawley or Lister hooded rats. Second, in the study of Depoortere et al. (1997b), the significant PPI reduction in Wistar rats as compared to Sprague-Dawley rats was even proposed as an animal model for drug screening. More surprisingly, differences in the PPI response were found between two lines of the same Lewis inbred strain (HAN and SSN; Stöhr et al. 1999).

In view of the variability of the startle and PPI responses in relation to the genetic background of the rats, it seems essential to describe here the influence of the 
strain on IR-induced PPI deficits. As already mentioned above, IR can modify startle reactivity, and this effect also seems to be strain dependent. With respect to Sprague-Dawley and Lister hooded rats, IR has generally been shown to increase startle amplitude (Geyer et al. 1993; Wilkinson et al. 1994; Varty and Higgins 1995; Bakshi et al. 1998), although in more recent studies no effect of IR was found (Varty et al. 1999a, 1999b; Weiss et al. 2000). In our own studies using Wistar rats, IR did not modify startle amplitude (Domeney and Feldon 1998; Weiss et al. 1999; Weiss et al. 2000). Despite the fact that methodological differences may account for the discrepancies between studies, some of our findings also suggest that the effect of IR on startle reactivity depends on the specific batch of animals (I. Weiss, personal observation).

Across several laboratories, PPI deficits seem to be consistently found in isolated rats from the SpragueDawley strain (Geyer et al. 1993; Varty and Geyer 1998; Bakshi and Geyer 1999; Varty et al. 1999a, 2000; Weiss et al. 2000, 2001). The same is true for Lister hooded rats, which also show reliable PPI deficits consequent to IR (Geyer et al. 1993; Varty and Higgins 1995; Varty et al. 1999b; Weiss et al. 2000). However, several studies performed in our laboratory revealed the fragility of the IR-induced PPI effect using rats from the Wistar strain (Domeney and Feldon 1998; Weiss et al. 1999). We further confirmed this fragility in a very recent study, where IR-induced PPI deficits were seen only in SpragueDawley and Lister hooded rats but not in Wistar rats (Weiss et al. 2000). Finally, IR-induced PPI deficits were not found in Fawn hooded (Hall et al. 1997a) or Lewis (Varty and Geyer 1998) rats, but were apparent in Fischer rats (Varty and Geyer 1998).

In conclusion, the present data emphasise the necessity of choosing carefully the strain of rats used in studies investigating either the pharmacological or environmental/developmental induction of PPI deficits. Surprisingly, some rat strains may even be resistant to these two methods of PPI deficit induction. Indeed, as demonstrated by Varty and Geyer (1998), rats from the Lewis strain do not show any PPI impairment after either apomorphine treatment or IR.

\section{Gender}

In human studies, PPI has been described as being sexually dimorphic, with women demonstrating lower PPI than men (Abel et al. 1998; Della Casa et al. 1998; Swerdlow et al. 1993a, 1999). The latter result was not accompanied by changes in startle reflex amplitude. Reproductive hormones interact with brain substrates underlying the processes of sensorimotor gating to modulate the PPI response (Swerdlow et al. 1997). In women, PPI undergoes changes across the menstrual cycle, with reduced PPI during peaks of oestrogen, suggesting that lower levels of PPI per se are not always indicative of pathology. Furthermore, the sensitivity of women in de- tecting the prepulse was not modulated by reproductive hormones, and their startle reflex amplitudes were stable across the menstrual cycle (Swerdlow et al. 1997). In the rat, and consistent with the sexual dimorphism apparent in humans, PPI is greater in males than in females (Koch 1998; Faraday et al. 1999; Lehmann et al. 1999b; Weiss et al. 2001). In line with the human evidence, Koch (1998) demonstrated that female rats show variations of their PPI levels during the oestrus cycle, with lower PPI during the pro-oestrous phase when oestrogen levels are elevated (in comparison with other phases of the cycle or with male PPI). Generally, this higher PPI in males was also accompanied by enhanced startle reflex relative to females (Blaszczyk and Tajchert 1996; Lehmann et al. 1999b; but see Koch 1998). In conclusion, the above findings emphasise the necessity of controlling for gender effect in studies investigating the mechanisms underlying the PPI response.

In view of the above findings, it was thought important to investigate the influence of gender on IR-induced PPI deficits. However, until now, all studies looking at the effect of IR on PPI were performed in male rats. We therefore recently investigated the startle and PPI responses of isolated females and males (Sprague-Dawley strain). This study revealed that in females IR does not produce any PPI reduction, whereas in males significant PPI deficits were apparent (Weiss et al. 2001). Although males from the latter study demonstrated greater PPI and startle responses relative to females, confirming studies reported in the literature (Blaszczyk and Tajchert 1996; Koch 1998; Faraday et al. 1999; Lehmann et al. 1999b), startle was not modified by IR and of importance, no interaction between gender and IR was seen. Consequently, the present findings support the contention that male subjects are better suited for IR-induced disruption of PPI as an animal model for drug screening.

In view of IR being an animal model for sensorimotor gating impairments in schizophrenia, this sexual dimorphism in the IR-induced effects may represent an important finding that supports the face validity of the model. Although the present finding may require further confirmation, it supports the contention that males are more sensitive than females to environmental manipulation (Weiner et al. 1987; Feldon et al. 1990; Peters et al. 1991; Lehmann et al. 1998; Weiss et al. 2001). Furthermore, this finding is in line with the higher incidence of developmental disturbances in the male human population (Seeman 1997; Castle et al. 1998; Torgalsboen 1999). For example, in schizophrenia, the onset of the symptoms is earlier in males, and the rate and severity of the disease are higher among males than females (Nicole et al. 1992). A mechanistic explanation for the above can be related to the fact that oestrogen is known to activate DA release in the nucleus accumbens and striatum, and to affect dopamine receptor sensitivity, which might in turn modify the dopaminergic modulation of PPI (Hruska 1986; Fink et al. 1996). Furthermore, it is tempting to propose that during development, through an influence on brain maturation, oestrogen has "protec- 
tive" effects against the deleterious modifications following IR on brain structures involved in PPI. In view of the above-mentioned findings, SI-induced PPI deficits could represent a relevant animal model for the study of the mechanisms underlying the sexual dimorphism present in schizophrenia, and increases the face validity of the model.

\section{Caging condition during the SI procedure}

Manipulation of the social environment of rats during development implies also the control of the husbandry conditions during rearing, in order to exclude any interaction with the behavioural effect of the social deprivation. Nevertheless, after scrutiny of the literature on SI and PPI, it is difficult to obtain clear information on the caging conditions used. For most of the studies it can be deduced that the authors used plastic cages containing sawdust (e.g. Bakshi and Geyer 1999; Varty et al. 2000), although in some cases the caging condition is not mentioned at all (Bristow et al. 1995; Hall et al. 1997a; Varty and Geyer 1998). Wilkinson et al. (1994), on the other hand, specified that isolated and grouped rats were reared in grid-floor cages. Therefore, in a recent study, we reared socially isolated and grouped rats from the Wistar strain in two different types of cages, i.e. solidbottom cages containing sawdust or wire grid-floor cages with a plastic under-hanging tray (Weiss et al. 1999). The caging condition during rearing played a major role in the IR-induced effects on acoustic startle and PPI in adult animals. When reared in sawdust cages, isolates exhibited reduced PPI relative to grouped controls (trend level), whereas in animals reared in grid-floor cages, isolates and grouped controls had similar PPI. In contrast, the acoustic startle response was not modified by the caging condition. The striking result of this experiment is that the lack of an IR effect on PPI was associated with a significant PPI reduction in grouped rats reared on grid-floors relative to grouped rats reared on sawdust. A possible explanation for the latter effect could be that rearing grouped rats in grid-floor cages represents a type of chronic stressor, which can impair the sensorimotor gating abilities of adult animals. In addition, human handling is totally lacking in animals reared in grid-floor cages and thus may render the animals much more sensitive to the stress of handling during the first experimental testing. It should be noted here that Wilkinson et al. (1994) reported a significant PPI deficit after IR in Lister hooded rats reared on grid-floor cages. Although our experiment was not conducted in the optimal strain to show IR-induced PPI deficits (partially explaining the fragility of IR-induced effects on PPI in rats reared on sawdust; see above), the present findings suggest that the likelihood of obtaining IR-induced PPI deficits is higher in animals reared in cages containing sawdust versus grid floors. Finally, it stresses the issue of controlling the husbandry conditions during IR to avoid interactions with the behavioural effects of the manipulation.
Experimental interactions with locomotor activity testing

In the majority of studies investigating the effects of IR on PPI, the locomotor activity of the animals was also assessed, the latter being performed either before (Geyer et al. 1993; Wilkinson et al. 1994; Varty et al. 1999b, 2000) or after (Bakshi and Geyer 1999; Weiss et al. 1999, 2000) testing for PPI of the startle reflex. Testing the locomotor activity of animals in an open field can represent a stressful experience. First, it implicates human handling, which can be very stressful for naive, non-handled isolates and second, the novelty of the environment itself is known to enhance corticosterone release even in control grouped rats (Gentsch et al. 1981; Hall 1998). As in the majority of studies locomotor activity is the first test performed after the period of IR, it could be argued that this "stressful" manipulation may influence the subsequent PPI response. This potential experimental interaction between locomotor testing in an open field environment and PPI was investigated by Domeney and Feldon (1998) in Wistar rats. They demonstrated that prior exposure to activity testing abolishes IR-induced PPI deficits. When the activity testing was performed between two PPI sessions conducted with the same animals, an IR-induced PPI deficit was found only in the first session, the animals being still experimentally naive. This finding may explain partly why in experimental designs where PPI was tested after locomotor activity, the IR effect on PPI was not seen across the range of prepulse intensities tested but was restricted to one intensity (i.e. 8 dB above background noise; Geyer et al. 1993; Wilkinson et al. 1994). The reason for the experimental influence of locomotor activity testing on PPI is not known, but it may be related to differential dopamine activation. In conclusion, social isolates should ideally be naive before PPI testing.

Modality and parameters of the stimulation in the PPI paradigm

As already mentioned, PPI is a multimodal phenomenon that can be assessed in humans and rats using acoustic, tactile, or visual stimuli. The choice of modality also seems to be important in demonstrating robust IRinduced PPI effects. In rats, Varty et al. (Varty and Geyer 1998; Varty et al. 1999a) failed to obtain a PPI deficit after IR when the rats were tested using a light for the prepulse, whereas a significant IR-induced PPI deficit was found using an acoustic prepulse. In humans also, PPI deficits were found in schizotypical personality disorder using acoustic but not tactile PPI (Cadenhead et al. 1993). We should note here that using parameters other than varying prepulse intensities to modulate PPI could also affect the effect of IR. For example, Varty et al. (1999b) found a more robust IR-induced PPI deficit when using variable prepulse-pulse intervals than when using variable prepulse intensities (the deficit was apparent only at one intensity). 
Ontogeny of the SI-induced PPI deficit

In view of the relevance of the SI model for drug screening, the ontogeny of the SI-induced PPI deficit has been carefully studied in the last few years. SI entails the disadvantage of being a time- and money-consuming approach for inducing PPI deficits, and therefore several studies have evaluated the minimal length of SI necessary to obtain a PPI effect and the temporal window during which PPI deficits can be seen in adult rats. We review here some of those temporal parameters that were found to be critical for improving such a model.

First, the age of the rats at onset of the SI procedure is a critical factor. Wilkinson et al. (1994) have demonstrated that SI-induced PPI deficits were apparent only when the animals were socially isolated from weaning (IR) and not if they were isolated in adulthood (IH). In other words, SI-induced PPI deficit seems to be a developmentally specific model, providing further support for its relevance for schizophrenia. Importantly, this finding was not associated with a differential influence of IR or IH on acoustic startle, since both IR and IH rats demonstrated an increased reflex amplitude as compared to grouped controls (Wilkinson et al. 1994).

Second, whereas some behavioural outcomes consequent to IR, such as locomotor hyperactivity, are already seen in pre-pubertal rats (2 weeks of post-weaning SI, see Bakshi and Geyer 1999), SI effects on PPI are apparent only when the animals reach early adulthood (Bakshi and Geyer 1999; Varty et al. 1999a). In the study of Bakshi and Geyer (1999), Sprague-Dawley isolated rats showed PPI deficits already after 4 weeks of IR, whereas Lister hooded isolated rats demonstrated PPI deficits only after 6-7 weeks of continuous SI. Consequently, IR-induced PPI impairment seems to emerge around the time of puberty. Furthermore, the study of Varty et al. (1999a) raised the issue that PPI should be investigated after a continuous period of SI from weaning, since resocialization of the animals between the IR period (4 weeks post-weaning) and the PPI test (performed in adulthood, 8 weeks post-weaning) abolished the PPI deficit. Therefore, in most studies, a minimum of 8 consecutive weeks following weaning are used to obtain an isolation-induced PPI deficit. In our own studies, using either Wistar or Lister hooded rats, a minimum of 12 weeks of IR was needed to see PPI deficits as a consequence of the manipulation (I. Weiss, unpublished observations). This post-pubertal emergence of PPI deficits in isolates is of interest and is consistent with the delayed PPI effect seen after neonatal lesions of the ventral hippocampus (Lipska et al. 1995).

Finally, a recent study performed in our laboratory suggested that long periods of SI and/or repeated PPI testing could lower the PPI deficit shown by isolated rats (Weiss et al. 2001). In contrast, it could be argued that longer IR periods will reinforce the PPI deficit, although there may be a confounding influence of age. In addition, several studies performed in our laboratory (Weiss et al. 1999, 2000, 2001) and others (Geyer et al. 1993) were indicative of a progressive weakening of the SIinduced PPI deficit as a function of repeated PPI testing. In contrast, in a study of Bakshi et al. (1998), two PPI tests were needed to obtain a significant SI-induced PPI deficit, because the first PPI session did not yield a SI effect. Nevertheless, a first PPI session may be necessary to reduce the variability within the experimental groups by counterbalancing the animals for PPI level before starting a pharmacological manipulation. Varty and Higgins (1995) have indicated that when repeated testing is used, the PPI test sessions should be separated from each other by at least 14 days, as shorter intervals weaken the SI-induced PPI deficit. Furthermore, as we have reported in a previous study (Domeney and Feldon 1998; and see above), a behavioural test (open field) performed before PPI can abolish SI-induced PPI deficits. It is thus reasonable to think that a first PPI session could interact with the SI-induced effect (similarly to an open field session) to reduce the deficit in a second PPI test.

Consequently, we would like to conclude this section by presenting unpublished data from a recent study performed in our laboratory that aimed at answering these two remaining questions: "Will a long IR period produce a stronger PPI deficit than a short IR period?" and, "Is repeated PPI testing detrimental or beneficial for the IR effect?" These two issues were addressed simultaneously in one large cross-sectional study conducted in male adult Sprague-Dawley rats. Continuous IR was performed from weaning (21 days of age) without resocialisation until PPI testing in adulthood. The behavioural responses of isolates in the PPI paradigm were compared with those of grouped controls. Isolated and grouped rats were reared in the same holding room, so that isolated rats maintained olfactory, auditory, and visual contacts with their grouped counterparts thoughout the studies. All animals were reared in solid bottom Macrolon cages containing sawdust, and were disturbed only for cleaning purposes. The first startle and PPI responses of naive animals were assessed after either 12 (group 1), 16 (group 2), 20 (group 3) or 24 (group 4) weeks of SI from weaning. Furthermore, the question regarding the effect of repeated testing on the SI-induced PPI disruption was answered by testing group 1 four times, group 2 three times and group 3 twice. After each period of IR, the rats from the different groups were tested at the same time, in order to control for age and naivety.

The acoustic startle reflex and the PPI response were assessed as reported elsewhere (Weiss et al. 2000). Briefly, the startle reflex and the PPI response were measured in four sound-attenuated startle chambers (SR-LAB, San Diego Instruments, San Diego, Calif., USA), which were illuminated and ventilated. In order to show an accurate picture of the PPI effects produced by IR, we present the percentage of PPI for all four prepulse intensities tested $(4,8,12$ and $16 \mathrm{~dB}[\mathrm{~A}]$ above a background noise of $68 \mathrm{~dB}[\mathrm{~A}])$. The pulse was a $120 \mathrm{~dB}[\mathrm{~A}]$ acoustic stimulus. In addition, to further clarify the issue of the robustness of the IR-induced PPI deficit, we added an analysis of effect size. The method was elaborated by Cohen and 
Fig. 1 Effect of long IR periods on the social isolationinduced PPI deficit in naive adult rats. Means \pm SEM of percentage PPI are presented for group-reared (GRP) and isolation-reared (ISO) male rats from the Sprague-Dawley strain. Group 1 (10 GRP and 10 ISO) was tested after 12 weeks, group 2 (10 GRP and 9 ISO) after 16 weeks, group 3 (10 GRP and 10 ISO) after 20 weeks, and group 4 (10 GRP and 10 ISO) after 24 weeks of continuous isolation rearing. The $P$-value of the main factor of Rearing (GRP versus ISO) derived form the analysis of variance is presented for each group, together with the effect size (d) of the IR treatment. $* P<0.05$

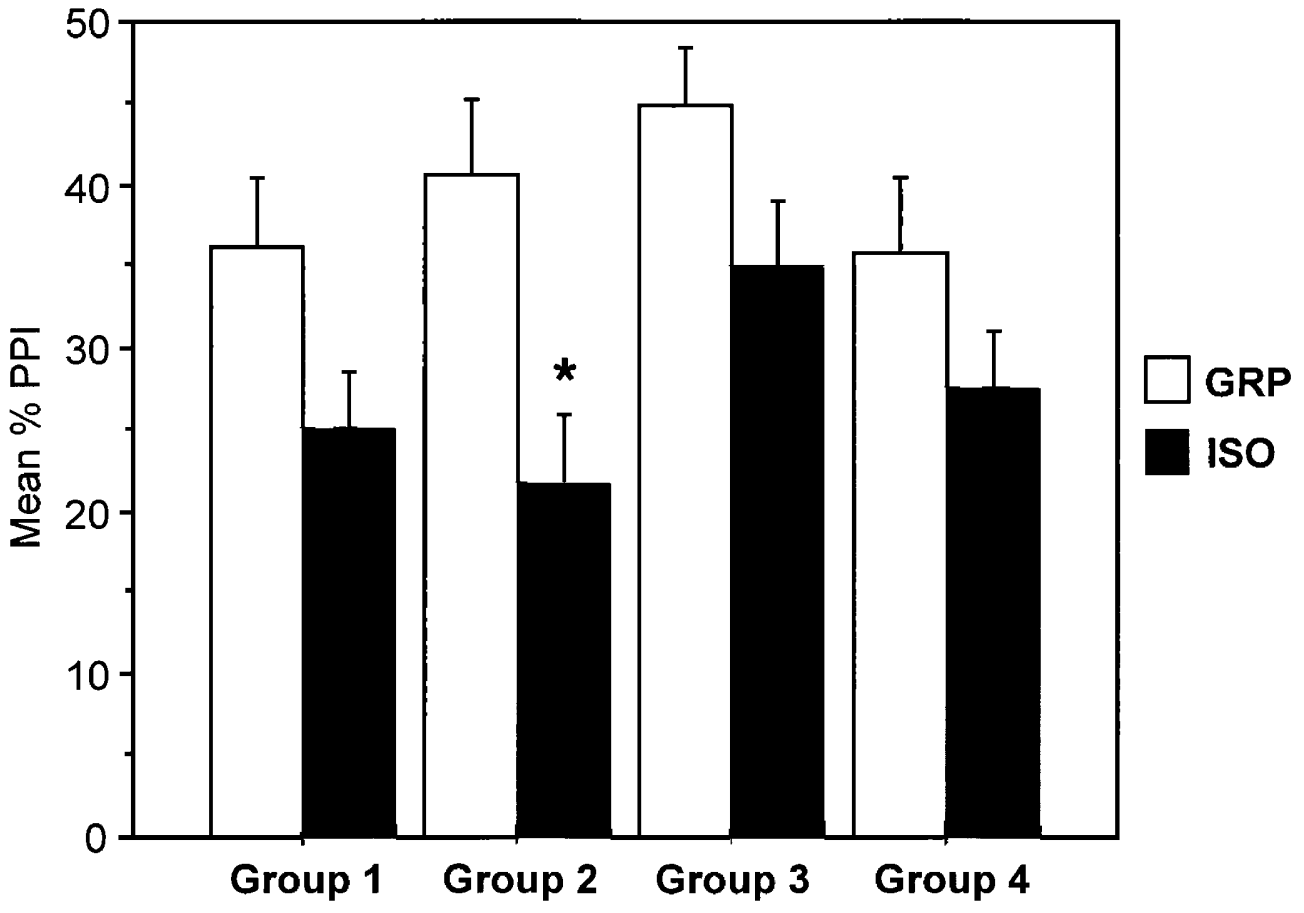

$\begin{array}{llll}p=0.17 & p<0.05 & p=0.13 & p=0.25 \\ d=0.32 & d=0.50 & d=0.35 & d=0.27\end{array}$

is described elsewhere (Cohen 1988). Briefly, using a statistical parametric analysis, the effect size index (or d) is calculated as follows: [(mean PPI groupA-mean PPI groupB)/common within-population standard deviation]. Several effect sizes are described, with $\mathrm{d}=0.2$ being a small effect, $\mathrm{d}=0.5$ being a medium effect, and $\mathrm{d}=0.8$ being a large effect. The implication of these estimates is that for a $50 \%$ chance of rejecting the null hypothesis, using a two-tailed t-test and an $\alpha$ of less than 0.05, 200, 30 and 10 subjects per group will be needed for a small, medium and large effect size, respectively (Cohen 1988; Table 2.3.5). The findings of this original study are described below and are based on all subjects that took part in the experiment (i.e. no exclusion of statistical outliers was allowed for this overall presentation of the results, but see below).

\section{Effect of long IR periods on the SI-induced PPI deficit in naive adult rats}

We investigated the startle and the PPI responses of separate groups of naive rats tested after 12, 16, 20 or 24 weeks of continuous IR from weaning. Each of the four experimental groups (groups 1-4) consisted of nine or ten isolated and ten grouped rats, originating, for each subgroup of isolates or grouped rats, from nine or ten different mothers. This was done to avoid any genetical or behavioural bias due to maternal care ("litter effects") (Lehmann et al. 2000a). As depicted in Fig. 1, SIinduced PPI deficits were apparent for all groups, at least at a trend level. The latter was indeed confirmed by an overall significant main effect of Rearing [grouped versus isolated rats; $F(1,71)=10.6 ; P<0.01]$. The lack of a Group $(12,16,20$ or 24 weeks of IR) $\times$ Rearing interaction $[F(3,71)=0.4, P>0.75]$ indicated that the extent of the SI-induced PPI deficit was not significantly different between the four groups. However, a significant Group $\times$ Rearing $\times$ Prepulse intensity $(72,76,80$ and $84 \mathrm{~dB})$ interaction $[F(3,213)=2.3, P<0.02]$ reflected variations between the groups in the expression of SI-induced PPI deficits across the four prepulse intensities. As can be seen in Fig. 2 (graphics with bold frame), although IR reduced the percentage of PPI, in no group (1-4) was the deficit apparent across all prepulse intensities tested. In addition, there was no statistical evidence for a reduction of mean levels of PPI as a function of length of the IR period (see Fig. 1). Furthermore, the startle amplitude was not affected by the length of the IR period. In regard to the present findings, we can conclude that the length of the IR period and/or the age per se of the animals do not modify considerably the PPI deficit induced by chronic IR. Rather, obtaining robust deficient PPI after IR seems to be dependent on the specific group of rats; group 2 for example demonstrated IR-induced PPI deficits for two prepulse intensities (76 and $84 \mathrm{~dB}$ ), whereas for groups 1 and 3, IR-induced PPI disruption was apparent only at $72 \mathrm{~dB}$ (see Fig. 2). To further examine this issue, we conducted an analysis of the size of IR effect, separately for each experimental group. The latter analysis confirmed the parametric analysis (ANOVA) performed on percentage PPI and revealed that IR had a medium size effect in group 2, and a small effect in groups 1, 3 and 4 (see Table 1, left panel). 
Fig. 2 Complete diagram of the PPI responses of the different experimental Groups of the cross-sectional design study. Means \pm SEM of percentage PPI are presented for each prepulse intensity tested (i.e. 72, 76, 80 and $84 \mathrm{~dB}[\mathrm{~A}])$. Group 1 (10 GRP and 10 ISO) was tested after 12,16, 20 and 24 weeks, group 2 (10 GRP and 9 ISO) after 16, 20 and 24 weeks, group 3 (10 GRP and 10 ISO) after 20 and 24 weeks, and group 4 (10 GRP and 10 ISO) after 24 weeks of continuous isolation rearing. The graphs with a bold frame present the first PPI test of each group. $* P<0.05$; $+0.05<P<0.10$
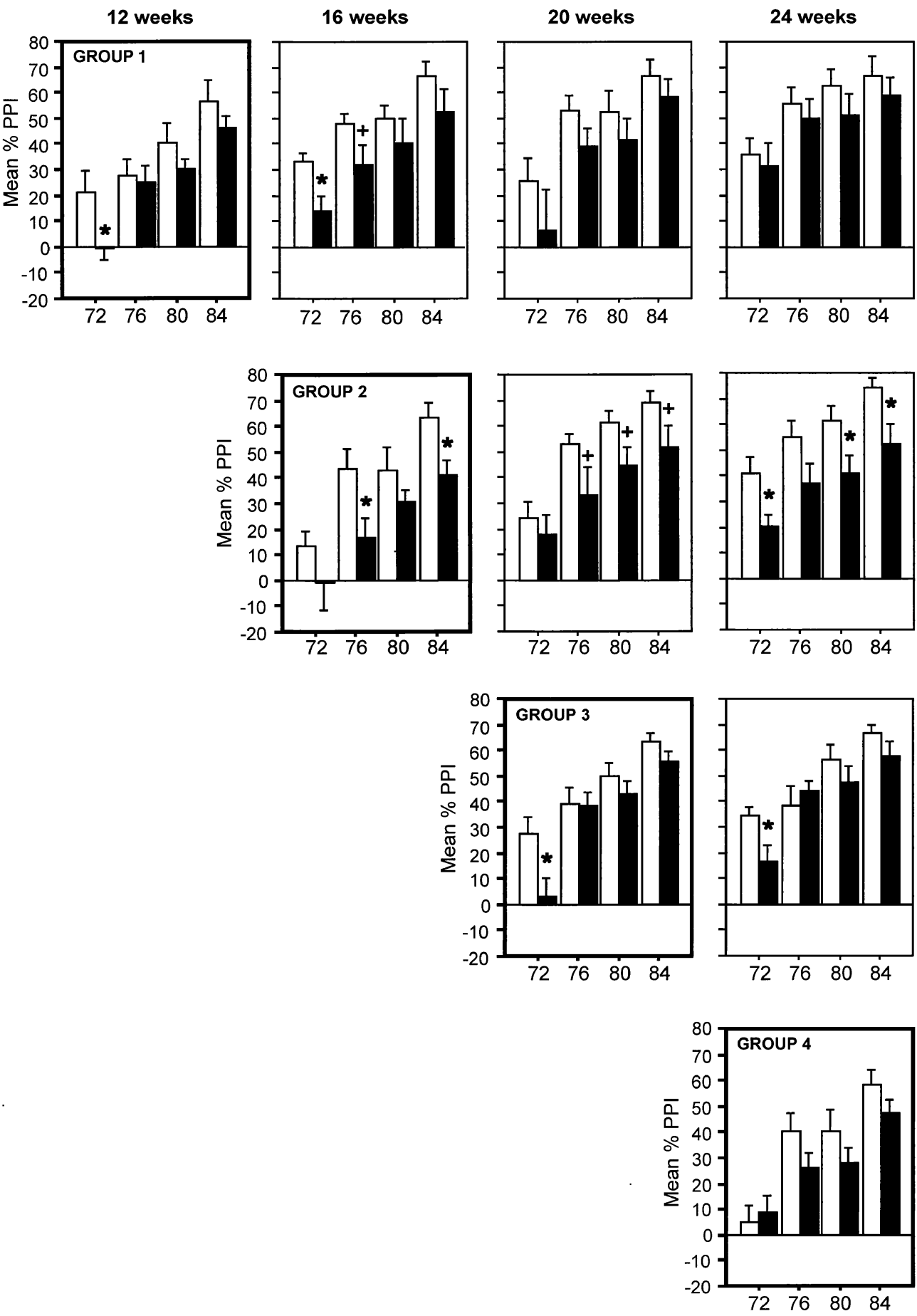

\section{Effect of repeated testing on the SI-induced PPI deficit}

To investigate the consequences of repeated PPI sessions on the IR-induced PPI deficit, three out of the four experimental groups already used above were further studied in additional PPI tests. Group 1 was tested after 12, 16, 20 and 24 weeks of chronic IR (three repeated tests), group 2 was tested after 16, 20 and 24 weeks of IR (two repeated tests) and group 3 was tested after 20 and 24 weeks of IR (one repeated test). The analyses performed for each group, with PPI testing as a repeated measurements factor, revealed that for groups 1 and 3 , a general IR-induced effect was apparent but only at a trend level [Rearing main effect; $F(1,18)=2.6, P=0.12$ and $F(1,18)=3.8, P=0.06$, respectively]. In group 2 , there was a significant main effect of $\operatorname{IR}[F(1,17)=7.9$, $P<0.02]$. However, for the three groups, no interaction between the repetition of PPI sessions and the IR effect was evident ( $P>0.78$ in all groups). In other words, when an IR-induced PPI disruption was apparent in the first test session (for example, in group 2; see Fig. 3), it was maintained over three tests, 4 weeks apart, but when the 
Table 1 Summary of the results with a comparison of several statistical analyses conducted on the same data. The IR effect on the startle reflex, the percentage PPI and the effect size are presented for all PPI test sessions performed with each group. In the left panel, data were analysed using all the 79 animals, whereas the right panel presents data after exclusion of three control rats, reducing the $n$ numbers: Group 1 (9 GRP and 10 ISO), group 2
(9 GRP and 9 ISO), group 3 (9 GRP and 10 ISO). There was no exclusion of rats in group 4 (10 GRP and $10 \mathrm{ISO})$. The capital letters represent significant differences $(P<0.05)$ between group- and isolation-reared rats. The small letters represent a trend for a difference between group- and isolation-reared rats $(0.05<P<0.10)$. Effect size: $d=0.2$ indicates a small effect, $d=0.5$ indicates a medium effect and $\mathrm{d}=0.8$ indicates a large effect

\begin{tabular}{|c|c|c|c|c|c|c|c|c|}
\hline & \multicolumn{4}{|c|}{ No exclusion } & \multicolumn{4}{|c|}{ Exclusion of 3 rats } \\
\hline & 12 weeks & 16 weeks & 20 weeks & 24 weeks & 12 weeks & 16 weeks & 20 weeks & 24 weeks \\
\hline \multicolumn{9}{|c|}{ Startle reflex } \\
\hline $\begin{array}{l}\text { Group } 1 \\
\text { Group } 2 \\
\text { Group } 3 \\
\text { Group } 4\end{array}$ & GRP $<$ ISO & $\begin{array}{l}\text { GRP }=I S O \\
\text { GRP }=I S O\end{array}$ & $\begin{array}{l}\text { GRP=ISO } \\
\text { GRP=ISO } \\
\text { GRP=ISO }\end{array}$ & $\begin{array}{l}\text { GRP }=I S O \\
\text { GRP }>\text { ISO } \\
\text { GRP=ISO } \\
\text { GRP=ISO }\end{array}$ & GRP $<$ ISO & $\begin{array}{l}\text { GRP }=I S O \\
\text { GRP }=I S O\end{array}$ & $\begin{array}{l}\text { GRP=ISO } \\
\text { GRP=ISO } \\
\text { GRP=ISO }\end{array}$ & $\begin{array}{l}\text { GRP }=\text { ISO } \\
\text { GRP }>\text { ISO } \\
\text { GRP }=\text { ISO } \\
\text { GRP }=\text { ISO }\end{array}$ \\
\hline \multicolumn{9}{|c|}{$\%$ Prepulse inhibition } \\
\hline $\begin{array}{l}\text { Group } 1 \\
\text { Group } 2 \\
\text { Group } 3 \\
\text { Group } 4\end{array}$ & $\mathrm{GRP}=\mathrm{ISO}$ & $\begin{array}{l}\text { grp }>\text { iso } \\
\text { GRP>ISO }\end{array}$ & $\begin{array}{l}\text { GRP=ISO } \\
\text { grp>iso } \\
\text { GRP=ISO }\end{array}$ & $\begin{array}{l}\text { GRP }=I S O \\
\text { GRP }>\text { ISO } \\
\text { GRP=ISO } \\
\text { GRP }=\text { ISO }\end{array}$ & GRP $>$ ISO & $\begin{array}{l}\text { GRP }>\text { ISO } \\
\text { GRP }>\text { ISO }\end{array}$ & $\begin{array}{l}\text { GRP=ISO } \\
\text { grp >iso } \\
\text { GRP }>\text { ISO }\end{array}$ & $\begin{array}{l}\mathrm{GRP}=\mathrm{ISO} \\
\mathrm{GRP}>\mathrm{ISO} \\
\mathrm{GRP}=\mathrm{ISO} \\
\mathrm{GRP}=\mathrm{ISO}\end{array}$ \\
\hline \multicolumn{9}{|c|}{ Effect size } \\
\hline $\begin{array}{l}\text { Group } 1 \\
\text { Group } 2 \\
\text { Group } 3 \\
\text { Group } 4\end{array}$ & 0.32 & $\begin{array}{l}0.44 \\
0.50\end{array}$ & $\begin{array}{l}0.31 \\
0.43 \\
0.35\end{array}$ & $\begin{array}{l}0.18 \\
0.59 \\
0.28 \\
0.27\end{array}$ & 0.62 & $\begin{array}{l}0.57 \\
0.57\end{array}$ & $\begin{array}{l}0.37 \\
0.47 \\
0.59\end{array}$ & $\begin{array}{l}0.32 \\
0.76 \\
0.33 \\
0.27\end{array}$ \\
\hline
\end{tabular}

IR effect was not apparent in the first session (for example, in groups 1 and 3), additional PPI sessions did not help to clarify the picture (see Fig. 3). Taken together, the present findings support the contention presented before that obtaining a robust IR-induced PPI deficit depends on the specific group of animals, especially when using only ten rats per group. Another interesting finding was that mean percentage PPI levels increased over repeated testing [ group $1, F(3,54)=9.5, P<0.001$ and group 2, $F(2,34)=7.9, P<0.01$; see Fig. 3], confirming a previous report (Martinez et al. 2000). There was, however, a significant reduction of the startle amplitude as a function of repeated testing (type of long-term habituation) for groups $1[F(3,54)=4.1, P<0.02]$ and $3[F(1,18)=4.5$, $P<0.05]$ but not for group $2(P>0.22)$, but there was no general main effect of IR on the startle reflex amplitude in any group. Finally, the size of the IR effect on PPI was basically stable across PPI testing for all the groups, although the IR effect in session 4 of group 1 was particularly low as compared to the effect size in the other sessions (see Table 1, left panel).

\section{Comparison of several statistical analyses for the SI-induced PPI deficit}

Since no interaction between SI and either repeated testing or length of SI period could be detected, we considered each of the experimental groups separately from each other and each PPI session within one group independently. This provided us with ten virtual samples of the SI-induced effect on startle and PPI. When an analysis on the mean percentage PPI was conducted for each of the ten "samples", only two out of ten (sessions 1 and 3 for group 2) yielded a significant SI effect, and two out of ten (group 1, session 1 and group 2, session 2) demonstrated a trend towards a PPI reduction after SI (see Table 1, left panel). Consequently, in six out of ten groups, the SI-induced PPI reduction was not significant. Isolation rearing modified the amplitude of the startle reflex in only two groups and in opposite directions (increase in group 1, session 1 and decrease in group 2, session 3). Finally, an analysis on the size of the SI effect was conducted for each sample (see Table 1, left panel).

As can be seen in Table 1 (left panel), for a still unknown reason some experimental groups of rats are more likely to show SI-induced effects on PPI (e.g. group 2) and when a deficit is apparent, it remains stable across several test sessions. More generally, a mean effect size of $\mathrm{d}=0.37$ (ranging from $\mathrm{d}=0.18$ to $\mathrm{d}=0.59$; see Table 1 , left panel) was found over the ten sample groups, which represents a relatively small SI effect. This would suggest that under similar circumstances (strain, gender or husbandry condition), and using a two-tailed $t$-test to compare the PPI responses of grouped and isolated rats, at least 50 rats per group will be required to have a $50 \%$ chance of demonstrating a significant SI-induced PPI disruption (Cohen 1988; Table 2.3.5).

Before presenting our conclusions, we present an additional analysis of the data, which discarded animals that had a PPI level outside the range of two standard deviations above and below the mean, in two PPI tests or more. Only three rats out of 79 were thus excluded, all of them belonging to the so-called "control" groups (one grouped rat each in groups 1,2 and 3). The data are presented in Table 1 (right panel). In contrast to the situa- 
Fig. 3 Effect of repeated testing on the SI-induced PPI deficit. Means \pm SEM of percentage PPI are presented collapsed over the four prepulse intensities tested (i.e. 72, 76, 80 and $84 \mathrm{~dB}[\mathrm{~A}]$ ) for group 1 (10 GRP and 10 ISO), group 2 (10 GRP and 9 ISO), group 3 (10 GRP and 10 ISO), and group 4 (10 GRP and 10 ISO). The graphs with a bold frame present the first PPI test of each group. $* P<0.05 ;+0.05<P<0.10$
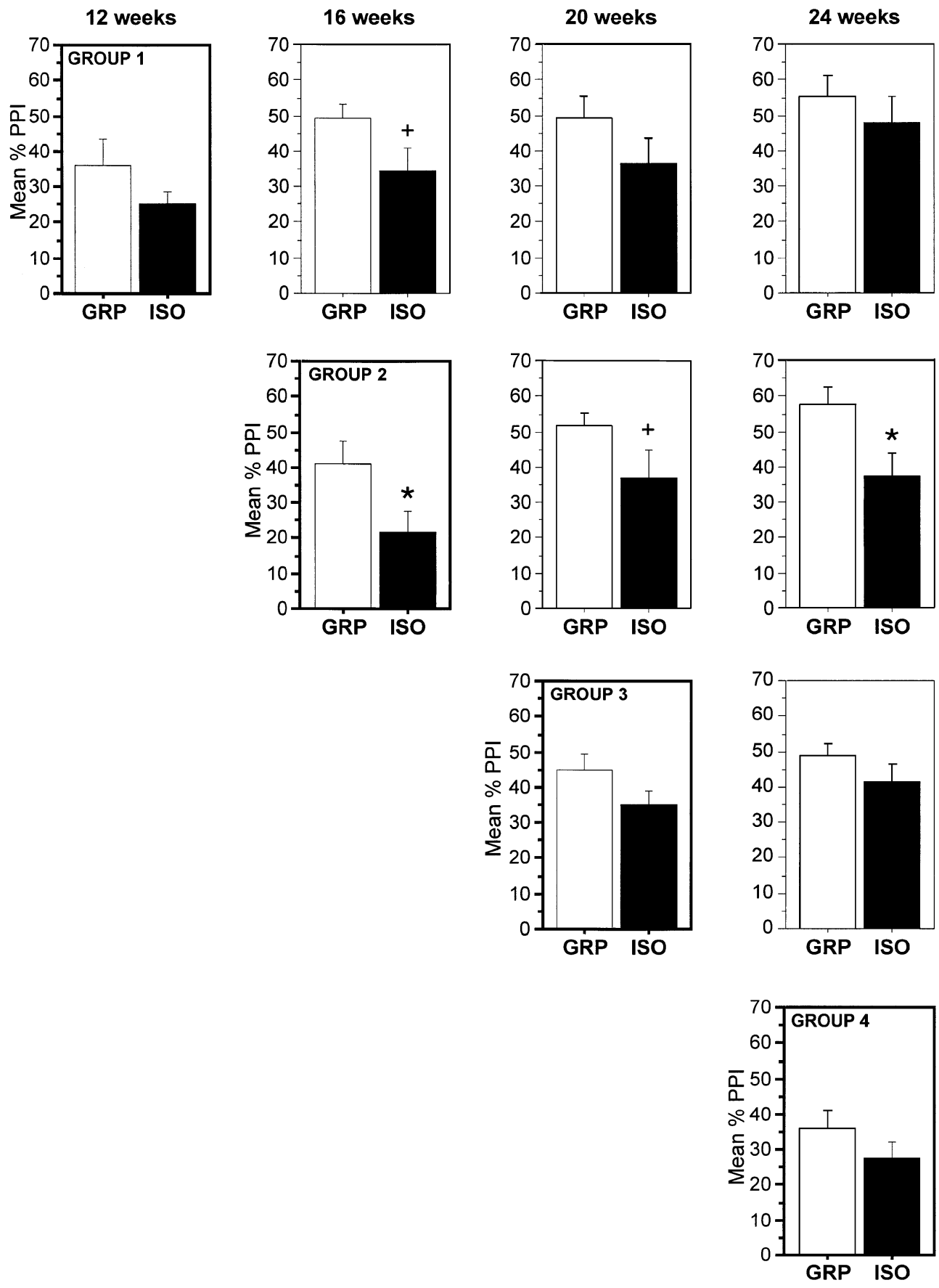

tion where all the animals were included, now half of the ten virtual sample groups demonstrated a significant IRinduced percentage PPI disruption (group 1, sessions 1 and 2; group 2, sessions 1 and 3; group 3, session 1) and one sample demonstrated a trend towards an IR effect on PPI (group 2, session 2). In addition, the effect size was considerably increased, with a mean effect size of $\mathrm{d}=0.49$ (ranging from $\mathrm{d}=0.27$ to $\mathrm{d}=0.76$ ), which represents a medium SI effect. Under these conditions, only 30 rats per group would now be required to have a $50 \%$ chance of demonstrating a significant IR-induced PPI deficit under the same experimental conditions (Cohen 1988; Table 2.3.5). In other words, a minimal exclusion of three rats out of 79 can significantly modify the robustness of the findings. This is even more striking because the three outlier rats were not environmentally manipulated and, in addition, our attempt to "characterise" them in terms of differences from the other rats in weight, startle amplitude to pulse or startle amplitude to prepulse, did not yield any significant predictor.

In summary, all the findings presented in this section support the contention that the PPI disruption induced by SI is a very sensitive model and that a number of methodological parameters can considerably affect the size of the SI-induced deficit. Therefore, a correct interpretation of the findings may require the use of different statistical 
analyses of the same data, in order to judge the robustness of the SI effect on PPI. In this context, the analysis based on effect size may be highly relevant, because it measures the extent of a treatment effect in a way that allows a direct comparison with other studies. Regarding the ontogeny of the SI-induced PPI deficit, the picture already elaborated by Bakshi et al. (1998) and Varty et al. (1999a) is somehow filled out by the present data, and it suggests the presence of a "time-window" for the effects of SI on PPI. Although the statement is strain dependent, effects on PPI should be seen when SI is conducted without interruption from weaning and for a period ranging from 6-7 weeks to approximately 20 weeks. Finally, the present findings do not support the view that repeated PPI testing is either beneficial (Bakshi et al. 1998) or detrimental (Weiss et al. 2001) for the establishment of reliable PPI disruption following IR.

\section{Combined environmental manipulations}

To the best of our knowledge, only a few studies have investigated the effects on PPI of combinations of environmental manipulations. The rationale for combining environmental manipulations is an attempt to enhance the "brain pathology" that leads to disruption of a behaviour, such as PPI (for a more detailed elaboration on the subject, see Weiss et al. 2001). Two such combined studies were conducted in our laboratories. A first study combined prenatal stress (restraint stress from day 15 to day 22 of pregnancy) and MS (6 h/day on postnatal days 12, 14, 16 and 18; partial social deprivation) and was performed in male and female Wistar rats (Lehmann et al. 2000b). A second study combined MS (4 h/day from postnatal day 1 to 21 ; complete social deprivation) and IR and was performed in male and female SpragueDawley rats (Weiss et al. 2001). In the study of Lehmann et al. (2000b), MS, which did not affect PPI on its own, antagonised the PPI increase induced by prenatal stress, both in males and females. In contrast, the startle reflex amplitude was affected only in MS males, towards a reduction. In the study of Weiss et al. (2001), no interaction between MS and IR was found for PPI or startle reactivity, irrespective of rat gender. IR alone, however, produced a significant PPI deficit in male rats (without modifying the startle amplitude) but not in females, whereas MS alone did not affect the PPI or the startle reflex of the animals.

In conclusion, the combinations described above led to only minor effects in terms of behavioural consequences for sensorimotor gating abilities, and as such do not necessarily represent relevant animal models for schizophrenia. Indeed, these models do not "offer" more than each environmental manipulation conducted separately, since no additive effects were found either on the amplitude of the startle reflex or on the PPI response.

\section{Summary and conclusions}

Among the three environmental manipulations reviewed, it is the procedure of IR that demonstrates the most profound consequences for startle reflex and PPI. Thus, there seems to be a dissociation between the effects of pre-weaning (EH and MS) and post-weaning (IR) manipulations on sensorimotor gating abilities of adult rats. Although it is true that $\mathrm{IH}$, which does not affect PPI, is also a manipulation conducted after weaning, this procedure is performed in mature animals and thus may be considered insufficient (too late in ontogeny) to affect PPI. It is striking that not one of the pre-weaning manipulations conducted in our laboratory, including $\mathrm{EH}$, nonhandling and MS for $1 \times 24-h$ or $4 \times 6-h$ or $21 \times 4-h$, in Wistar or in Sprague-Dawley male and female rats, altered the PPI response of adult animals. However, Ellenbroek et al. (1998; Ellenbroek and Cools 2000) have demonstrated PPI disruption following a single 24-h MS on postnatal day 9 in Wistar rats. In contrast, the PPI disruption induced by post-weaning IR has been observed in several laboratories, including ours. We should note here that generally in comparison to the pharmacological induction of PPI deficits, the effects on PPI produced by environmental manipulations, such as IR, are less extensive. This would probably also explain why the PPI consequences of early environmental manipulations are so critically sensitive to experimental conditions. Although this IR model seems to present face, predictive and construct validity for modelling schizophrenia, it requires careful consideration of a number of methodological parameters, such as rat strain, gender, caging condition during IR, or parameters of the stimulation in the PPI paradigm, which weaken considerably the reliability of the model and consequently its usefulness in screening new compounds with potential antipsychotic activity. Therefore, further validations and refinements of the model are required, and in this context, the analysis of effect size may be considered as a relevant tool to facilitate inter-laboratory comparisons. Nevertheless, this IR-induced PPI disruption model provides promising features for understanding the physiological and neurochemical changes produced by early stressful experience, which may prove to be helpful in elucidating the neurobiology of schizophrenia.

It is thus tempting to speculate on neurobiological substrates possibly involved in the disruption of PPI following chronic social isolation. Although literature on neuroanatomical/neurochemical modifications produced by the manipulation is very limited, several studies have revealed neurochemical alterations within the medial prefrontal cortex (mPFC) of isolated rats (Crespi et al. 1992; Jones et al. 1992; Heidbreder et al. 2000). Furthermore, several lesion and infusion studies performed in normal adult rats suggest that the $\mathrm{mPFC}$ is involved in the neural circuitry of PPI, but not in that of LI (Bubser and Koch 1994; Ellenbroek et al. 1996; Lacroix et al. 1998; Broersen et al. 1999; Lacroix et al. 2000a). We should mention here again that LI is not affected by SI. 
Therefore, the selective effect of SI on PPI could be linked to a mPFC alteration, possibly via a subtle "environmentally-induced lesion" (Weiss et al. 2000). Furthermore, this hypothesis of a SI-induced "environmental lesion" centered on the mPFC fits with the perseverative behaviours shown by isolated rats (Morgan et al. 1975, 1977; Gluck and Pearce 1977; Dalrymple-Alford and Benton 1984; Feldon et al. 1990), mPFC lesioned animals (Doar et al. 1987; Morgan et al. 1993; Morgan and LeDoux 1995; Hauser 1999), and by human schizophrenics (Frith and Done 1983). Finally, the mPFC is clearly involved in emotional processes that underlie negative emotional states such as anxiety, stress or panic (Morgan et al. 1993; Barbas 1995; Morgan and LeDoux 1995; Lacroix et al. 2000b). However, evidence from neurochemical studies of brains of isolates (Jones et al. 1991, 1992; Heidbreder et al. 2000) suggests that rather than inducing a neural dysfunction limited to a single brain structure, SI is more likely to induce imbalances between neural connections within the cortico-striatolimbic circuitry. Although the rat prefrontal cortex is fully mature at weaning in terms of neurogenesis, some neural connections with other structures may not be completely established and thus SI may interact with this maturation (S. Bayer, personal communication). In fact, morphological changes in the brain of social isolates have been recently studied. In line with the neurochemical evidence of an alteration of the prefrontal cortex following IR, Singh-Curry et al. (1998) have demonstrated a significant decrease in NADPH-diaphorase neuronal density in the prefrontal cortex of isolated rats. In addition, subcortical structures also seem to be developmentally sensitive to IR. Varty et al. (1999b) have found a reduction of synaptic content in the dentate gyrus of social isolates, as reflected by diminished synaptophysin immunoreactivity. Interestingly, a similar finding has also been reported in human schizophrenic patients (Eastwood and Harrison 1995). A reduction in density of the dendritic spines of spiny neurons within the dorsolateral striatum of isolated rats has been reported by Comery et al. (1995). Although, these different anatomical alterations are suggestive of a complex influence of IR on brain development, they do not always correlate with the behavioural abnormalities demonstrated by the isolates. Therefore, more studies are now required to investigate neuroanatomical modifications at the cortical and subcortical levels induced by the development of rats in chronic SI, in order to understand how SI influences the interactions between the different structures of the cortico-meso-limbic circuitry. The latter will certainly shed light on the mechanisms by which IR leads to long-term changes in behaviour, particularly in sensorimotor gating abilities.

Acknowledgements The studies presented in the present review, which were conducted in the Behavioural Neurobiology Laboratory, were supported by the Swiss Federal Institute of Technology (Zurich, Switzerland). Isabelle Weiss was further supported by a grant from F. Hoffmann-LaRoche, Ltd (Basel, Switzerland). We would like to thank Dr. Chris Pryce and Dr. Olivier Raineteau for their insightful comments on the manuscript, Dr. Isabelle Allmann, Dr. Jacqueline Kupper, Sandra Egger, Thomas Karich, Natascha Häni and Monika Denger for their care of the animals, Peter Schmid for his valuable technical assistance and Bonnie Strehler for her precious secretarial help.

\section{References}

Abel K, Waikar M, Pedro B, Hemsley D, Geyer M (1998) Repeated testing of prepulse inhibition and habituation of the startle reflex: a study in healthy human controls. J Psychopharmacol $12: 330-337$

Abi-Dargham A, Rodenhiser J, Printz D, Zea-Ponce Y, Gil R, Kegeles LS, Weiss R, Cooper TB, Mann JJ, Van Heertum RL, Gorman JM, Laruelle M (2000) Increased baseline occupancy of $\mathrm{D}_{2}$ receptors by dopamine in schizophrenia. Proc Natl Acad Sci USA 97:8104-8109

Adler LE, Pachtman E, Franks RD, Pecevich M, Waldo MC, Freedman R (1982) Neurophysiological evidence for a defect in neuronal mechanisms involved in sensory gating in schizophrenia. Biol Psychiatry 17:639-654

Ahmed SH, Stinus L, Le Moal M, Cador M (1995) Social deprivation enhances the vulnerability of male Wistar rats to stressorand amphetamine-induced behavioral sensitization. Psychopharmacology 117:116-124

Anisman H, Zaharia MD, Meaney MJ, Merali Z (1998) Do earlylife events permanently alter behavioral and hormonal responses to stressors? Int J Dev Neurosci 16:149-164

Arnold SE, Hyman BT, Van Hoesen GW, Damasio AR (1991) Some cytoarchitectural abnormalities of the entorhinal cortex in schizophrenia. Arch Gen Psychiatry 48:625-632

Bachus SE, Kleinman JE (1996) The neuropathology of schizophrenia. J Clin Psychiatry 57:72-83

Bakshi VP, Geyer MA (1998) Multiple limbic regions mediate the disruption of prepulse inhibition produced in rats by the noncompetitive NMDA antagonist dizocilpine. J Neurosci 18: 8394-8401

Bakshi VP, Geyer MA (1999) Ontogeny of isolation rearinginduced deficits in sensorimotor gating in rats. Physiol Behav 67:385-392

Bakshi VP, Swerdlow NR, Braff DL, Geyer MA (1998) Reversal of isolation rearing-induced deficits in prepulse inhibition by seroquel and olanzapine. Biol Psychiatry 43:436-445

Barbas H (1995) Anatomic basis of cognitive-emotional interactions in the primate prefrontal cortex. Neurosci Biobehav Rev 19:499-510

Bast T, Zhang W, Feldon J, White IM (2000) Effects of MK801 and neuroleptics on prepulse inhibition: re-examination in two strains of rats. Pharmacol Biochem Behav 67:647-658

Bast T, Zhang W-N, Heidbreder C, Feldon J (2001) Hyperactivity and disruption of prepulse inhibition induced by $N$-methyl-Daspartate stimulation of the ventral hippocampus and the effects of pretreatment with haloperidol and clozapine. Neuroscience 103:325-335

Blaszczyk J, Tajchert K (1996) Sex and strain differences of acoustic startle reaction development in adolescent albino Wistar and hooded rats. Acta Neurobiol Exp 56:919-925

Bleuler E (1911) Dementia praecox or the group of schizophrenias. International Universities Press, New York

Bolino F, Di Michele V, Di Cicco L, Manna V, Daneluzzo E, Casacchia M (1994) Sensorimotor gating and habituation evoked by electro-cutaneous stimulation in schizophrenia. Biol Psychiatry 36:670-679

Braff D, Stone C, Callaway E, Geyer M, Glick I, Bali L (1978) Prestimulus effects on human startle reflex in normals and schizophrenics. Psychophysiology 15:339-343

Braff DL, Grillon C, Geyer MA (1992) Gating and habituation of the startle reflex in schizophrenic patients. Arch Gen Psychiatry 49:206-215

Braff DL, Swerdlow NR, Geyer MA (1999) Symptom correlates of prepulse inhibition deficits in male schizophrenic patients. Am J Psychiatry 156:596-602 
Bristow LJ, Landon L, Saywell KL, Tricklebank MD (1995) The glycine/NMDA receptor antagonist, L-701,324 reverses isolation-induced deficits in prepulse inhibition in the rat. Psychopharmacology 118:230-232

Broersen LM, Feldon J, Weiner I (1999) Dissociative effects of apomorphine infusions into the medial prefrontal cortex of rats on latent inhibition, prepulse inhibition and amphetamineinduced locomotion. Neuroscience 94:39-46

Brown JS, Kalish HI, Farber IE (1951) Conditioned fear as revealed by magnitude of startle response to an auditory stimulus. J Exp Psychol 41:317-328

Bubser M, Koch M (1994) Prepulse inhibition of the acoustic startle response of rats is reduced by 6-hydroxydopamine lesions of the medial prefrontal cortex. Psychopharmacology 113: 487-492

Cadenhead KS, Geyer MA, Braff DL (1993) Impaired startle prepulse inhibition and habituation in patients with schizotypal personality disorder. Am J Psychiatry 150:1862-1867

Campbell J, Spear LP (1999) Effects of early handling on amphetamine-induced locomotor activation and conditioned place preference in the adult rat. Psychopharmacology 143:183-189

Castellanos FX, Fine EJ, Kaysen D, Marsh WL, Rapoport JL, Hallett M (1996) Sensorimotor gating in boys with Tourette's syndrome and ADHD: preliminary results. Biol Psychiatry 39:33-41

Castle D, Sham P, Murray R (1998) Differences in distribution of ages of onset in males and females with schizophrenia. Schizophr Res 33:179-183

Cohen J (1988) Statistical power analysis for the behavioral sciences, 2nd edn. Lawrence Erlbaum, Hove, London

Comery TA, Shah R, Greenough WT (1995) Differential rearing alters spine density on medium-sized spiny neurons in the rat corpus striatum: evidence for association of morphological plasticity with early response gene expression. Neurobiol Learn Mem 63:217-219

Crespi F, Wright IK, Mobius C (1992) Isolation rearing of rats alters release of 5-hydroxytryptamine and dopamine in the frontal cortex: an in vivo electrochemical study. Exp Brain Res 88:495-501

Dalrymple-Alford JC, Benton D (1984) Behavioural inhibition and the age at social isolation in rats. Q J Exp Psychol 36B: $27-38$

Davis M (1986) Pharmacological and anatomical analysis of fear conditioning using the fear potentiated startle paradigm. Behav Neurosci 100:814-824

Davis M (1989) Sensitization of the acoustic startle reflex by footshock. Behav Neurosci 103:495-503

Davis M, Gendelman DS, Tischler MD, Gendelman PM (1982) A primary acoustic startle circuit: lesion and stimulation studies. J Neurosci 2:791-805

Davis M, Mansbach RS, Swerdlow NR, Campeau S, Braff DL, Geyer MA (1990) Apomorphine disrupts the inhibition of acoustic startle induced by weak prepulses in the rat. Psychopharmacology 102:1-4

Davis M, Falls WA, Campeau S, Kim M (1993) Fear-potentiated startle: a neural and pharmacological analysis. Behav Brain Res 58:175-198

Della Casa V, Höfer I, Weiner I, Feldon J (1998) The effects of smoking on acoustic prepulse inhibition in healthy men and women. Psychopharmacology 137:362-368

Depoortere R, Perrault G, Sanger DJ (1997a) Potentiation of prepulse inhibition of the startle reflex in rats: pharmacological evaluation of the procedure as a model for detecting antipsychotic activity. Psychopharmacology 132:366-374

Depoortere R, Perrault G, Sanger DJ (1997b) Some, but not all, antipsychotic drugs potentiate a low level of prepulse inhibition shown by rats of the Wistar strain. Behav Pharmacol 8: 364-372

Doar B, Finger S, Almli CR (1987) Tactile-visual acquisition and reversal learning deficits in rats with prefrontal cortical lesions. Exp Brain Res 66:432-434

Domeney A, Feldon J (1998) The disruption of prepulse inhibition by social isolation in the Wistar rat: how robust is the effect? Pharmacol Biochem Behav 59:883-890
Eastwood SL, Harrison PJ (1995) Decreased synaptophysin in the medial temporal lobe in schizophrenia demonstrated using immunoautoradiography. Neuroscience 69:339-343

Egan MF, Weinberger DR (1997) Neurobiology of schizophrenia. Curr Opin Neurobiol 7:701-707

Einon DF, Morgan MJ (1977) A critical period for social isolation in the rat. Dev Psychobiol 10:123-132

Ellenbroek BA, Cools AR (1995) Maternal separation reduces latent inhibition in the conditioned taste aversion paradigm. Neurosci Res Commun 17:27-33

Ellenbroek BA, Cools AR (2000) The long-term effects of maternal deprivation depend on the genetic background. Neuropsychopharmacology 23:99-106

Ellenbroek BA, Budde S, Cools AR (1996) Prepulse inhibition and latent inhibition: the role of dopamine in the medial prefrontal cortex. Neuroscience 75:535-542

Ellenbroek BA, van den Kroonenberg PT, Cools AR (1998) The effects of an early stressful life event on sensorimotor gating in adult rats. Schizophr Res 30:251-260

Faraday MM, O'Donoghue VA, Grunberg NE (1999) Effects of nicotine and stress on startle amplitude and sensory gating depend on rat strain and sex. Pharmacol Biochem Behav 62: 273-284

Feifel D, Priebe K (1999) The effects of subchronic haloperidol on intact and dizocilpine-disrupted sensorimotor gating. Psychopharmacology 146:175-179

Feldon J, Weiner I (1988) Long-term attentional deficit in nonhandled males: possible involvement of the dopaminergic system. Psychopharmacology 95:231-236

Feldon J, Avnimelech-Gigus N, Weiner I (1990) The effects of pre- and postweaning rearing conditions on latent inhibition and partial reinforcement extinction effect in male rats. Behav Neural Biol 53:189-204

Feldon J, Lehmann J, Pryce C, Weiss I (2000) Rat latent inhibition and prepulse inhibition are sensitive to different manipulations of the social environment: a comprehensive study of the environmental approach to neurodevelopmental models of schizophrenia. In: Myslobodsky MS, Weiner I (eds) Contemporary issues in modeling psychopathology. Kluwer, Boston, pp 231-245

Finamore TL, Port RL (2000) Developmental stress disrupts habituation but spares prepulse inhibition in young rats. Physiol Behav 69:527-530

Fink G, Sumner BE, Rosie R, Grace O, Quinn JP (1996) Estrogen control of central neurotransmission: effect on mood, mental state, and memory. Cell Mol Neurobiol 16:325-344

Frankland PW, Ralph MR (1995) Circadian modulation in the rat acoustic startle circuit. Behav Neurosci 109:43-48

Freedman R, Adler LE, Waldo MC, Pachtman E, Franks RD (1983) Neurophysiological evidence for a defect in inhibitory pathways in schizophrenia: comparison of medicated and drug-free patients. Biol Psychiatry 18:537-551

Friston KJ, Liddle PF, Frith CD, Hirsch SR, Frackowiak RS (1992) The left medial temporal region and schizophrenia. A PET study. Brain 115:367-382

Frith CD, Done DJ (1983) Stereotyped responding by schizophrenic patients on a two-choice guessing task. Psychol Med 13:779-786

Fulford AJ, Marsden CA (1998) Effect of isolation-rearing on conditioned dopamine release in vivo in the nucleus accumbens of the rat. J Neurochem 70:383-390

Gamallo A, Villanua A, Trancho G, Fraile A (1986) Stress adaptation and adrenal activity in isolated and crowded rats. Physiol Behav 36:217-221

Gardner EB, Boitano JJ, Mancino NS, D’Amico DP (1975) Environmental enrichment and deprivation: effects on learning, memory and exploration. Physiol Behav 14:321-327

Gentsch C, Lichtsteiner M, Feer H (1981) Locomotor activity, defecation score and corticosterone levels during an openfield exposure: a comparison among individually and group-housed rats, and genetically selected rat lines. Physiol Behav 27:183-186

Gentsch C, Lichtsteiner M, Kraeuchi K, Feer H (1982) Different reaction patterns in individually and socially reared rats during exposures to novel environments. Behav Brain Res 4:45-54 
Gentsch C, Lichtsteiner M, Frischknecht HR, Feer H, Siegfried B (1988) Isolation-induced locomotor hyperactivity and hypoalgesia in rats are prevented by handling and reversed by resocialization. Physiol Behav 43:13-16

Geyer MA, Braff DL (1987) Startle habituation and sensorimotor gating in schizophrenia and related animal models. Schizophr Bull 13:643-668

Geyer MA, Wilkinson LS, Humby T, Robbins TW (1993) Isolation rearing of rats produces a deficit in prepulse inhibition of acoustic startle similar to that in schizophrenia. Biol Psychiatry $34: 361-372$

Giralt M, Armario A (1989) Individual housing does not influence the adaptation of the pituitary-adrenal axis and other physiological variables to chronic stress in adult male rats. Physiol Behav 45:477-481

Gluck JP, Pearce HE (1977) Acquisition and extinction of an operant response in differentially reared rats. Dev Psychobiol 10: 143-149

Graham FK (1975) The more or less startling effects of weak prestimulation. Psychophysiology 12:238-248

Greenough TW, Madden TC, Fleischmann TB (1972) Effects of isolation, daily handling, and enriched rearing on maze learning. Psychonom Sci 27:279-280

Grillon C, Ameli R, Charney DS, Krystal J, Braff D (1992) Startle gating deficits occur across prepulse intensities in schizophrenic patients. Biol Psychiatry 32:939-943

Hall FS (1998) Social deprivation of neonatal, adolescent, and adult rats has distinct neurochemical and behavioral consequences. Crit Rev Neurobiol 12:129-162

Hall FS, Huang S, Fong G (1997a) Effects of isolation-rearing on acoustic startle and pre-pulse inhibition in Wistar and Fawn Hooded rats. Ann NY Acad Sci 821:542-544

Hall FS, Humby T, Wilkinson LS, Robbins TW (1997b) The effects of isolation-rearing of rats on behavioural responses to food and environmental novelty. Physiol Behav 62:281-290

Harlow HF, Harlow MK (1962) Social deprivation in monkeys. Sci Am 207:136-146

Hatch AM, Wiberg GS, Zawidzka Z, Cann M, Airth JM, Grice HC (1965) Isolation syndrome in the rat. Toxicol Appl Pharmacol 7:737-745

Hauser MD (1999) Perseveration, inhibition and the prefrontal cortex: a new look. Curr Opin Neurobiol 9:214-222

Heckers S, Rauch SL, Goff D, Savage CR, Schacter DL, Fischman AJ, Alpert NM (1998) Impaired recruitment of the hippocampus during conscious recollection in schizophrenia. Nat Neurosci 1:318-323

Heidbreder CA, Weiss IC, Domeney AM, Pryce C, Homberg J, Hedou G, Feldon J, Moran MC, Nelson P (2000) Behavioral, neurochemical and endocrinological characterization of the early social isolation syndrome. Neuroscience 100:749-768

Hoffman DC, Donovan H, Cassella JV (1993) The effects of haloperidol and clozapine on the disruption of sensorimotor gating induced by the noncompetitive glutamate antagonist MK-801. Psychopharmacology 111:339-344

Hoffman HS, Ison JR (1980) Reflex modulation in the domain of startle: I Some empirical findings and their implications for how the nervous system processes sensory input. Psychol Rev 87: $175-189$

Holson RR (1986) Feeding neophobia: a possible explanation for the differential maze performance of rats reared in enriched or isolated environments. Physiol Behav 38:191-201

Holson RR, Scallet AC, Ali SF, Sullivan P, Gough B (1988) Adrenocortical, beta-endorphin and behavioral responses to graded stressors in differentially reared rats. Physiol Behav 42:125130

Holson RR, Scallet AC, Ali SF, Turner BB (1991) "Isolation stress" revisited: isolation-rearing effects depend on animal care methods. Physiol Behav 49:1107-1118

Hruska RE (1986) Elevation of striatal dopamine receptors by estrogen: dose and time studies. J Neurochem 47:1908-1915

Hutchison KE, Swift R (1999) Effect of $d$-amphetamine on prepulse inhibition of the startle reflex in humans. Psychopharmacology 143:394-400
Jones GH, Marsden CA, Robbins TW (1991) Behavioural rigidity and rule-learning deficits following isolation-rearing in the rat: neurochemical correlates. Behav Brain Res 43:35-50

Jones GH, Hernandez TD, Kendall DA, Marsden CA, Robbins TW (1992) Dopaminergic and serotonergic function following isolation rearing in rats: study of behavioural responses and postmortem and in vivo neurochemistry. Pharmacol Biochem Behav 43:17-35

Keith VA, Mansbach RS, Geyer MA (1991) Failure of haloperidol to block the effects of phencyclidine and dizocilpine on prepulse inhibition of startle. Biol Psychiatry 30:557-566

Kinney GG, Wilkinson LO, Saywell KL, Tricklebank MD (1999) Rat strain differences in the ability to disrupt sensorimotor gating are limited to the dopaminergic system, specific to prepulse inhibition, and unrelated to changes in startle amplitude or nucleus accumbens dopamine receptor sensitivity. J Neurosci 19:5644-5653

Klarner A, Koch M, Schnitzler HU (1998) Induction of Fos-protein in the forebrain and disruption of sensorimotor gating following $N$-methyl-D-aspartate infusion into the ventral hippocampus of the rat. Neuroscience 84:443-452

Knable MB, Weinberger DR (1997) Dopamine, the prefrontal cortex and schizophrenia. J Psychopharmacol 11:123-131

Koch M (1998) Sensorimotor gating changes across the estrous cycle in female rats. Physiol Behav 64:625-628

Koch M (1999) The neurobiology of startle. Prog Neurobiol 59: $107-128$

Koch M, Bubser M (1994) Deficient sensorimotor gating after 6-hydroxydopamine lesion of the rat medial prefrontal cortex is reversed by haloperidol. Eur J Neurosci 6:1837-1845

Koch M, Schnitzler HU (1997) The acoustic startle response in rats - circuits mediating evocation, inhibition and potentiation. Behav Brain Res 89:35-49

Koch M, Klarner A, Schnitzler HU (1999) Lesions of the rat piriform cortex prevent long-lasting sensorimotor gating deficits induced by stimulation of the ventral hippocampus. Neurosci Lett 275:195-198

Koch M, Schmid A, Schnitzler HU (2000) Role of nucleus accumbens dopamine $D_{1}$ and $D_{2}$ receptors in instrumental and Pavlovian paradigms of conditioned reward. Psychopharmacology 152:67-73

Kodsi MH, Swerdlow NR (1994) Quinolinic acid lesions of the ventral striatum reduce sensorimotor gating of acoustic startle in rats. Brain Res 643:59-65

Kumari V, Soni W, Sharma T (1999) Normalization of information processing deficits in schizophrenia with clozapine. Am J Psychiatry 156:1046-1051

Lacroix L, Broersen LM, Weiner I, Feldon J (1998) The effects of excitotoxic lesion of the medial prefrontal cortex on latent inhibition, prepulse inhibition, food hoarding, elevated plus maze, active avoidance and locomotor activity in the rat. Neuroscience 84:431-442

Lacroix L, Broersen LM, Feldon J, Weiner I (2000a) Effects of local infusions of dopaminergic drugs into the medial prefrontal cortex of rats on latent inhibition, prepulse inhibition and amphetamine induced activity. Behav Brain Res 107:111-121

Lacroix L, Spinelli S, Heidbreder C, Feldon J (2000b) Differential role of the medial and lateral prefrontal cortices in fear and anxiety. Behav Neurosci 114:1119-1130

Lang PJ, Bradley MM, Cuthbert BN (1990) Emotion, attention, and the startle reflex. Psychol Rev 97:377-395

Lehmann J, Feldon J (2000) Long-term biobehavioral effects of maternal separation in the rat: consistent or confusing? Rev Neurosci 11:383-408

Lehmann J, Stöhr T, Schuller J, Domeney A, Heidbreder C, Feldon J (1998) Long-term effects of repeated maternal separation on three different latent inhibition paradigms. Pharmacol Biochem Behav 59:873-882

Lehmann J, Pryce CR, Bettschen D, Feldon J (1999a) The maternal separation paradigm and adult emotionality and cognition in male and female Wistar rats. Pharmacol Biochem Behav 64:705-715 
Lehmann J, Pryce CR, Feldon J (1999b) Sex differences in the acoustic startle response and prepulse inhibition in Wistar rats. Behav Brain Res 104:113-117

Lehmann J, Pryce CR, Feldon J (2000a) Lack of effect of an early stressful life event on sensorimotor gating in adult rats. Schizophr Res 41:365-371

Lehmann J, Stöhr T, Feldon J (2000b) Long-term effects of prenatal stress experiences and postnatal maternal separation on emotionality and attentional processes. Behav Brain Res 107: 133-144

Leitner DS, Powers AS, Hoffman HS (1980) The neural substrate of the startle response. Physiol Behav 25:291-297

Levine S (1967) Maternal and environmental influences on the adrenocortical response to stress in weanling rats. Science 156:258-260

Levine S (1994) The ontogeny of the hypothalamic-pituitary-adrenal axis. The influence of maternal factors. Ann NY Acad Sci 746:275-288; discussion 289-293

Lipska BK, Jaskiw GE, Weinberger DR (1993) Postpubertal emergence of hyperresponsiveness to stress and to amphetamine after neonatal excitotoxic hippocampal damage: a potential animal model of schizophrenia. Neuropsychopharmacology 9:67-75

Lipska BK, Swerdlow NR, Geyer MA, Jaskiw GE, Braff DL, Weinberger DR (1995) Neonatal excitotoxic hippocampal damage in rats causes post-pubertal changes in prepulse inhibition of startle and its disruption by apomorphine. Psychopharmacology 122:35-43

Liu D, Diorio J, Tannenbaum B, Caldji C, Francis D, Freedman A, Sharma S, Pearson D, Plotsky PM, Meaney MJ (1997) Maternal care, hippocampal glucocorticoid receptors, and hypothalamic-pituitary-adrenal responses to stress. Science 277:16591662

Lovely RH, Pagano RR, Paolino RM (1972) Shuttle-box-avoidance performance and basal corticosterone levels as a function of duration of individual housing in rats. J Comp Physiol Psychol 81:331-335

Mansbach RS, Geyer MA (1989) Effects of phencyclidine and phencyclidine biologs on sensorimotor gating in the rat. Neuropsychopharmacology 2:299-308

Mansbach RS, Geyer MA, Braff DL (1988) Dopaminergic stimulation disrupts sensorimotor gating in the rat. Psychopharmacology 94:507-514

Mansbach RS, Brooks EW, Sanner MA, Zorn SH (1998) Selective dopamine $\mathrm{D}_{4}$ receptor antagonists reverse apomorphineinduced blockade of prepulse inhibition. Psychopharmacology 135:194-200

Marsh R, Hoffman HS, Stitt CL (1973) Temporal integration in the acoustic startle reflex of the rat. J Comp Physiol Psychol 82:507-511

Martinez ZA, Halim ND, Oostwegel JL, Geyer MA, Swerdlow NR (2000) Ontogeny of phencyclidine and apomorphineinduced startle gating deficits in rats. Pharmacol Biochem Behav 65:449-457

Matthews K, Hall FS, Wilkinson LS, Robbins TW (1996) Retarded acquisition and reduced expression of conditioned locomotor activity in adult rats following repeated early maternal separation: effects of prefeeding, $d$-amphetamine, dopamine antagonists and clonidine. Psychopharmacology 126:75-84

McIntosh J, Anisman H, Merali Z (1999) Short- and long-periods of neonatal maternal separation differentially affect anxiety and feeding in adult rats: gender-dependent effects. Brain Res Dev Brain Res 113:97-106

Meaney MJ, Aitken DH, van Berkel C, Bhatnagar S, Sapolsky RM (1988) Effect of neonatal handling on age-related impairments associated with the hippocampus. Science 239:766-768

Meaney MJ, Aitken DH, Viau V, Sharma S, Sarrieau A (1989) Neonatal handling alters adrenocortical negative feedback sensitivity and hippocampal type II glucocorticoid receptor binding in the rat. Neuroendocrinology 50:597-604

Meaney MJ, Aitken DH, Bhatnagar S, Sapolsky RM (1991) Postnatal handling attenuates certain neuroendocrine, anatomical, and cognitive dysfunctions associated with aging in female rats. Neurobiol Aging 12:31-38

Meaney MJ, Diorio J, Francis D, LaRocque S, O'Donnell D, Smythe JW, Sharma S, Tannenbaum B (1994) Environmental regulation of the development of glucocorticoid receptor systems in the rat forebrain. The role of serotonin. Ann NY Acad Sci 746:260-273; discussion 274:289-293

Meaney MJ, Diorio J, Francis D, Widdowson J, LaPlante P, Caldji C, Sharma S, Seckl JR, Plotsky PM (1996) Early environmental regulation of forebrain glucocorticoid receptor gene expression: implications for adrenocortical responses to stress. Dev Neurosci 18:49-72

Mednick SA, Machon RA, Huttunen MO, Bonett D (1988) Adult schizophrenia following prenatal exposure to an influenza epidemic. Arch Gen Psychiatry 45:189-192

Meltzer HY, Stahl SM (1976) The dopamine hypothesis of schizophrenia: a review. Schizophr Bull 2:19-76

Miachon S, Rochet T, Mathian B, Barbagli B, Claustrat B (1993) Long-term isolation of Wistar rats alters brain monoamine turnover, blood corticosterone, and ACTH. Brain Res Bull 32: $611-614$

Morgan M, Einon D (1975) Incentive motivation and behavioral inhibition in socially-isolated rats. Physiol Behav 15:405-409

Morgan MA, LeDoux JE (1995) Differential contribution of dorsal and ventral medial prefrontal cortex to the acquisition and extinction of conditioned fear in rats. Behav Neurosci 109: 681-688

Morgan MA, Romanski LM, LeDoux JE (1993) Extinction of emotional learning: contribution of medial prefrontal cortex. Neurosci Lett 163:109-113

Morgan MJ, Einon DF, Nicholas D (1975) The effects of isolation rearing on behavioural inhibition in the rat. Q J Exp Psychol 27:615-634

Morgan MJ, Einon D, Morris RGM (1977) Inhibition and isolation rearing in the rat: extinction and satiation. Physiol Behav $18: 1-5$

Morinan A, Leonard BE (1980) Some anatomical and physiological correlates of social isolation in the young rat. Physiol Behav 24:637-640

Nicole L, Lesage A, Lalonde P (1992) Lower incidence and increased male:female ratio in schizophrenia. Br J Psychiatry 161:556-557

Niesink RJ, van Ree JM (1983) Involvement of the pituitary-adrenal axis in socio-behavioral disturbances after short-term isolation. Physiol Behav 30:825-830

O'Callaghan E, Sham P, Takei N, Glover G, Murray RM (1991) Schizophrenia after prenatal exposure to 1957 A2 influenza epidemic. Lancet 337:1248-1250

Owen MJ, Lewis SW, Murray RM (1988) Obstetric complications and schizophrenia: a computed tomographic study. Psychol Med 18:331-339

Parwani A, Duncan EJ, Bartlett E, Madonick SH, Efferen TR, Rajan R, Sanfilipo M, Chappell PB, Chakravorty S, Gonzenbach S, Ko GN, Rotrosen JP (2000) Impaired prepulse inhibition of acoustic startle in schizophrenia. Biol Psychiatry 47: $662-669$

Perry W, Braff DL (1994) Information-processing deficits and thought disorder in schizophrenia. Am J Psychiatry 151:363367

Perry W, Geyer MA, Braff DL (1999) Sensorimotor gating and thought disturbance measured in close temporal proximity in schizophrenic patients. Arch Gen Psychiatry 56:277-281

Peters SL, Gray JA, Joseph MH (1991) Pre-weaning non-handling of rats disrupts latent inhibition in males, and results in persisting sex- and area-dependent increases in dopamine and serotonin turnover. Behav Pharmacol 2:215-223

Pham TM, Soderstrom S, Henriksson BG, Mohammed AH (1997) Effects of neonatal stimulation on later cognitive function and hippocampal nerve growth factor. Behav Brain Res 86:113-120

Phillips GD, Howes SR, Whitelaw RB, Wilkinson L, Robbins TW (1994) Isolation-rearing enhances the locomotor response to cocaine and a novel environment, but impairs the intravenous 
self-administration of cocaine. Psychopharmacology 115:407418

Pouzet B, Feldon J, Veenman CL, Yee BK, Richmond M, Nicholas J, Rawlins P, Weiner I (1999) The effects of hippocampal and fimbria-fornix lesions on prepulse inhibition. Behav Neurosci 113:968-981

Pryce CR, Bettschen D, Bahr NI, Feldon J (2001) Comparison of the effects of infant handling, isolation, and non-handling on acoustic startle, prepulse inhibition, locomotion, and HPA activity in the adult rat. Behav Neurosci 115:71-83

Pulver AE (2000) Search for schizophrenia susceptibility genes. Biol Psychiatry 47:221-230

Rebouças RCR, Schmidek WR (1997) Handling and isolation in three strains of rats affect open field, exploration, hoarding and predation. Physiol Behav 62:1159-1164

Rigdon GC (1990) Differential effects of apomorphine on prepulse inhibition of acoustic startle reflex in two rat strains. Psychopharmacology 102:419-421

Rigdon GC, Viik K (1991) Prepulse inhibition as a screening test for potential antipsychotics. Drug Dev Res 23:91-99

Rots NY, de Jong J, Workel JO, Levine S, Cools AR, De Kloet ER (1996) Neonatal maternally deprived rats have as adults elevated basal pituitary-adrenal activity and enhanced susceptibility to apomorphine. J Neuroendocrinol 8:501-506

Sahakian BJ, Robbins TW, Morgan MJ, Iversen SD (1975) The effects of psychomotor stimulants on stereotypy and locomotor activity in socially-deprived and control rats. Brain Res 84: 195-205

Sanchez MM, Aguado F, Sanchez-Toscano F, Saphier D (1995) Effects of prolonged social isolation on responses of neurons in the bed nucleus of the stria terminalis, preoptic area, and hypothalamic paraventricular nucleus to stimulation of the medial amygdala. Psychoneuroendocrinology 20:525-541

Seeman MV (1997) Psychopathology in women and men: focus on female hormones. Am J Psychiatry 154:1641-1647

Seeman P, Ulpian C, Bergeron C, Riederer P, Jellinger K, Gabriel E, Reynolds GP, Tourtellotte WW (1984) Bimodal distribution of dopamine receptor densities in brains of schizophrenics. Science 225:728-731

Shelton RC, Weinberger DR (1986) X-Ray computerized tomography studies of schizophrenia: a review and synthesis. In: Nasrallah HA, Weinberger DR (eds) The neurology of schizophrenia. Elsevier, Amsterdam, pp 207-250

Singh-Curry V, Varty GB, Geyer MA, Yee BK, Totterdell S (1998) Postweaning housing effects on nitric oxide-(NO) producing neurons of the prefrontal cortex in rats. ENA Meeting, Berlin. Eur J Neurosci 10S:28

Smith SJ, Lees AJ (1989) Abnormalities of the blink reflex in Gilles de la Tourette syndrome. J Neurol Neurosurg Psychiatry 52:895-898

Snyder SH (1976) The dopamine hypothesis of schizophrenia: focus on the dopamine receptor. Am J Psychiatry 133:197-202

Stanton ME, Gutierrez YR, Levine S (1988) Maternal deprivation potentiates pituitary-adrenal stress responses in infant rats. Behav Neurosci 102:692-700

Stöhr T, Szuran T, Pliska V, Feldon J (1999) Behavioural and hormonal differences between two Lewis rat lines. Behav Brain Res 101:163-172

Swerdlow NR, Geyer MA (1993) Clozapine and haloperidol in an animal model of sensorimotor gating deficits in schizophrenia. Pharmacol Biochem Behav 44:741-744

Swerdlow NR, Geyer MA (1998) Using an animal model of deficient sensorimotor gating to study the pathophysiology and new treatments of schizophrenia. Schizophr Bull 24:285-301

Swerdlow NR, Mansbach RS, Geyer MA, Pulvirenti L, Koob GF, Braff DL (1990) Amphetamine disruption of prepulse inhibition of acoustic startle is reversed by depletion of mesolimbic dopamine. Psychopharmacology 100:413-416

Swerdlow NR, Caine SB, Braff DL, Geyer MA (1992a) The neural substrates of sensorimotor gating of the startle reflex: a review of recent findings and their implications. J Psychopharmacol 6:176-190
Swerdlow NR, Caine SB, Geyer MA (1992b) Regionally selective effects of intracerebral dopamine infusion on sensorimotor gating of the startle reflex in rats. Psychopharmacology 108: 189-195

Swerdlow NR, Auerbach P, Monroe SM, Hartston H, Geyer MA, Braff DL (1993a) Men are more inhibited than women by weak prepulses. Biol Psychiatry 34:253-260

Swerdlow NR, Benbow CH, Zisook S, Geyer MA, Braff DL (1993b) A preliminary assessment of sensorimotor gating in patients with obsessive compulsive disorder. Biol Psychiatry 33:298-301

Swerdlow NR, Braff DL, Taaid N, Geyer MA (1994) Assessing the validity of an animal model of deficient sensorimotor gating in schizophrenic patients. Arch Gen Psychiatry 51:139154

Swerdlow NR, Lipska BK, Weinberger DR, Braff DL, Jaskiw GE, Geyer MA (1995a) Increased sensitivity to the sensorimotor gating-disruptive effects of apomorphine after lesions of medial prefrontal cortex or ventral hippocampus in adult rats. Psychopharmacology 122:27-34

Swerdlow NR, Paulsen J, Braff DL, Butters N, Geyer MA, Swenson MR (1995b) Impaired prepulse inhibition of acoustic and tactile startle response in patients with Huntington's disease. J Neurol Neurosurg Psychiatry 58:192-200

Swerdlow NR, Hartman PL, Auerbach PP (1997) Changes in sensorimotor inhibition across the menstrual cycle: implications for neuropsychiatric disorders. Biol Psychiatry 41:452-460

Swerdlow NR, Bakshi V, Waikar M, Taaid N, Geyer MA (1998) Seroquel, clozapine and chlorpromazine restore sensorimotor gating in ketamine-treated rats. Psychopharmacology 140:7580

Swerdlow NR, Geyer MA, Hartman PL, Sprock J, Auerbach PP, Cadenhead K, Perry W, Braff DL (1999) Sex differences in sensorimotor gating of the human startle reflex: all smoke? Psychopharmacology 146:228-232

Swerdlow NR, Braff DL, Geyer MA (2000a) Animal models of deficient sensorimotor gating: what we know, what we think we know, and what we hope to know soon. Behav Pharmacol 11:185-204

Swerdlow NR, Martinez ZA, Hanlon FM, Platten A, Farid M, Auerbach P, Braff DL, Geyer MA (2000b) Toward understanding the biology of a complex phenotype: rat strain and substrain differences in the sensorimotor gating-disruptive effects of dopamine agonists. J Neurosci 20:4325-4336

Takei N, Mortensen PB, Klaening U, Murray RM, Sham PC, O'Callaghan E, Munk-Jorgensen P (1996) Relationship between in utero exposure to influenza epidemics and risk of schizophrenia in Denmark. Biol Psychiatry 40:817-824

Torgalsboen AK (1999) Full recovery from schizophrenia: the prognostic role of premorbid adjustment, symptoms at first admission, precipitating events and gender. Psychiatry Res 88: $143-152$

Tsuang MT (1998) Recent advances in genetic research on schizophrenia. J Biomed Sci 5:28-30

Vallee M, Mayo W, Dellu F, Le Moal M, Simon H, Maccari S (1997) Prenatal stress induces high anxiety and postnatal handling induces low anxiety in adult offspring: correlation with stress-induced corticosterone secretion. J Neurosci 17:26262636

Varty GB, Geyer MA (1998) Effects of isolation rearing on startle reactivity, habituation, and prepulse inhibition in male Lewis, Sprague-Dawley, and Fischer F344 rats. Behav Neurosci 112: $1450-1457$

Varty GB, Higgins GA (1994) Differences between three rat strains in sensitivity to prepulse inhibition of an acoustic startle response: influence of apomorphine and phencyclidine pretreatment. J Psychopharmacol 8:148-156

Varty GB, Higgins GA (1995) Examination of drug-induced and isolation-induced disruptions of prepulse inhibition as models to screen antipsychotic drugs. Psychopharmacology 122:15-26

Varty GB, Braff DL, Geyer MA (1999a) Is there a critical developmental "window" for isolation rearing-induced changes in 
prepulse inhibition of the acoustic startle response? Behav Brain Res 100:177-183

Varty GB, Marsden CA, Higgins GA (1999b) Reduced synaptophysin immunoreactivity in the dentate gyrus of prepulse inhibition-impaired isolation-reared rats. Brain Res 824:197203

Varty GB, Paulus MP, Braff DL, Geyer MA (2000) Environmental enrichment and isolation rearing in the rat: effects on locomotor behavior and startle response plasticity. Biol Psychiatry 47: 864-873

Vollenweider FX, Umbricht D, Geyer MA, Hell D (2000) Effects of NMDA-antagonists and 5- $\mathrm{HT}_{2 \mathrm{~A}}$-agonists on prepulse inhibition in human volunteers. Schizophr Res 41:147

Wade SE, Maier SF (1986) Effects of individual housing and stressor exposure upon the acquisition of watermaze escape. Learn Motiv 17:287-310

Wan FJ, Swerdlow NR (1997) The basolateral amygdala regulates sensorimotor gating of acoustic startle in the rat. Neuroscience 76:715-724

Weike AI, Bauer U, Hamm AO (2000) Effective neuroleptic medication removes prepulse inhibition deficits in schizophrenia patients. Biol Psychiatry 47:61-70

Weinberg J, Smotherman WP, Levine S (1978) Early handling effects on neophobia and conditioned taste aversion. Physiol Behav 20:589-596

Weinberger DR (1987) Implications of normal brain development for the pathogenesis of schizophrenia. Arch Gen Psychiatry 44:660-669

Weinberger DR (1997) The biological basis of schizophrenia: new directions. J Clin Psychiatry 58:22-27

Weiner I, Schnabel I, Lubow RE, Feldon J (1985) The effects of early handling on latent inhibition in male and female rats. Dev Psychobiol 18:291-297

Weiner I, Feldon J, Ziv-Harris D (1987) Early handling and latent inhibition in the conditioned suppression paradigm. Dev Psychobiol 20:233-240

Weiss IC, Feldon J, Domeney AM (1999) Isolation rearing-induced disruption of prepulse inhibition: further evidence for fragility of the response. Behav Pharmacol 10:139-149
Weiss IC, Di Iorio L, Feldon J, Domeney AM (2000) Strain differences in the isolation-induced effects on prepulse inhibition of the acoustic startle response and on locomotor activity. Behav Neurosci 114:364-373

Weiss IC, Domeney AM, Moreau J-L, Russig H, Feldon J (2001) Dissociation between the effects of pre-weaning and/or postweaning social isolation on prepulse inhibition and latent inhibition in adult Sprague-Dawley rats. Behav Brain Res 121: 207-218

Wilkinson LS, Killcross SS, Humby T, Hall FS, Geyer MA, Robbins TW (1994) Social isolation in the rat produces developmentally specific deficits in prepulse inhibition of the acoustic startle response without disrupting latent inhibition. Neuropsychopharmacology 10:61-72

Wongwitdecha N, Marsden CA (1995) Isolation rearing prevents the reinforcing properties of amphetamine in a conditioned place preference paradigm. Eur J Pharmacol 279:99-103

Wongwitdecha N, Marsden CA (1996) Effects of social isolation rearing on learning in the Morris water maze. Brain Res 715: $119-124$

Wright IK, Upton N, Marsden CA (1991) Resocialisation of isolation-reared rats does not alter their anxiogenic profile on the elevated X-maze model of anxiety. Physiol Behav 50:11291132

Yee BK (2000) Cytotoxic lesion of the medial prefrontal cortex abolishes the partial reinforcement extinction effect, attenuates prepulse inhibition of the acoustic startle reflex and induces transient hyperlocomotion, while sparing spontaneous object recognition memory in the rat. Neuroscience 95:675-689

Zhang W, Pouzet B, Jongen-Relo AL, Weiner I, Feldon J (1999) Disruption of prepulse inhibition following $N$-methyl-D-aspartate infusion into the ventral hippocampus is antagonized by clozapine but not by haloperidol: a possible model for the screening of atypical antipsychotics. Neuroreport 10:25332538

Zimmerberg B, Shartrand AM (1992) Temperature-dependent effects of maternal separation on growth, activity, and amphetamine sensitivity in the rat. Dev Psychobiol 25:213-226 